\title{
Las Termas de Fregellae. Arquitectura, tecnología y cultura balnear en el Lacio durante los siglos III y II a.C.
}

\author{
Vasilis Tsiolis*
}

\section{Resumen}

El complejo termal de Fregellae (Lacio, Italia), recientemente descubierto, se suma a la larga serie de importantes edificios republicanos de esta colonia latina (328-125 a.C.), hallados durante las excavaciones dirigidas por el Prof. F. Coarelli. Las termas de Fregellae, un edificio monumental del denominado "tipo itálico", presenta al menos dos fases constructivas, que aportan nuevos datos sobre los orígenes y difusión de las prácticas de baño y la arquitectura balnear en el Lacio durante los siglos III y II a.C. El complejo balnear de la fase más reciente, fechado en el segundo cuarto del siglo II a.C., que sustituye a un edificio más antiguo, incluye varias salas para el baño templado y caliente, divididas en dos sectores (masculino y femenino), de las cuales al menos una estaba cubierta por una espectacular bóveda de medio punto, realizada en opus figlinum, de un tipo similar al que describe Vitruvio. Un hypocaustum, del que dispone una pequeña habitación, resulta ser el "verdadero" hipocausto más antiguo conocido hasta la fecha, hecho que demuestra cómo la teoría que atribuye la invención de este dispositivo a Sergio Orata ha de ser rectificada. Este elemento, junto a algunos restos de tubos cerámicos, probablemente utilizados para la calefacción parietal de la habitación con hipocausto, ponen de manifiesto el alto grado de progreso tecnológico alcanzado en este campo, en una época todavía temprana. Por lo que concierne al edificio de la primera fase, localizado bajo los cimientos de la fase posterior, la excavación ha permitido conocer en parte un complejo termal particularmente monumental, dotado de infraestructuras y tecnologías muy avanzadas, que remiten a las experiencias arquitectónicas de Magna Grecia y de Sicilia en los años centrales del siglo III a.C. Ambas fases del edificio de Fregellae constituyen, pues, los ejemplos más antiguos de baños públicos conocidos hasta la fecha en el contexto romano-itálico.

\section{Riassunto}

II complesso termale di Fregellae (Lazio, Italia), recentemente esplorato, si aggiunge alla lunga serie di importanti edifici repubblicani di questa colonia latina (328-125 a.C.) scoperti dagli scavi condotti dal Prof. F. Coarelli. Le terme di Fregellae, un edificio monumentale del cosidetto "tipo itálico", presenta al meno due fasi edilizie che offrono nuovi dati sulle origini e sulla diffusione delle partiche e dell'architettura balneari nel Lazio durante il III e il II secolo a.C. II complesso della fase più recente, databile nel secondo quarto del II secolo a.C., che sostituisce un edificio più antico, comprende varie stanze pel il bagno tiepido e caldo, divise in due settori (maschile e femminile), di cui al meno una era coperta da una impressionante volta a tutto sesto in opus figlinum, di un tipo molto simile a quello descritto da Vitruvio. Un hypocaustum di cui è dotata una piccola stanza, il più antico "vero" ipocausto finora noto, dimostra che la teoria sull'invenzione di questo dispositivo da Sergio Orata va rettificata. Questo elemento, insieme a alcuni resti di tubi ceramici, funzionali probabilmente al riscaldamento parietale della stanza con ipocausto, pongono di rilievo il progresso tecnologico raggiunto in questo campo, in un'epoca ancora precoce. Per quanto riguarda l'edificio di prima fase, localizzato sotto le fondazioni di seconda fase, I scavo ha permesso di conoscere in parte un complesso assai monumentale, dotato di infrastrutture e tecnologie molto avanzate, che rimandano alle esperienze architettoniche della Magna Grecia e della Sicilia degli anni centrali del III secolo a.C. Entrambi le fasi dell'edifico fregellano costituiscono gli esempi più antichi di edifici balneari pubblici finora noti nel mondo romano-italico.

\section{INTRODUCCIÓN}

El creciente interés mostrado en los últimos años por la investigación española hacia el ámbito termal, ha coincidido con la aparición de algunos de los más antiguos establecimientos balnea-

* Este artículo constituye un breve avance del estudio arquitectónico de las termas de Fregellae, que me ha sido encomendado por el Director de la excavación Prof. Filippo Coarelli, al que agradezco su confianza y generosidad. La publicación definitiva del edificio aparecerá próximamente en el volumen Fregellae IV. Le terme, ediciones Quasar, Roma, actualmente en fase de prepara- res denominados de tipo itálico conocidos hasta la fecha, en especial los localizados en L'Almoina (Valencia capital) y en Cabrera del Mar, junto a Mataró. El estudio de estos edificios y de otros análogos descubiertos fuera de las fronteras españolas, tiene en las termas mediorrepublicanas

ción. Deseo, así mismo, expresar mi agradecimiento a la Dra. Giovanna Battaglini, al Prof. Paolo Braconi, a la Prof. Rebeca Rubio, al Ing. Angelo Lisi, al Dr. Rudolf Känel, al Dr. David Nonnis, a Santiago Caballero y a todos los estudiantes y arqueólogos, muchos de ellos españoles, con los que he compartido durante quince años las mismas inquietudes del Proyecto Fregellae 


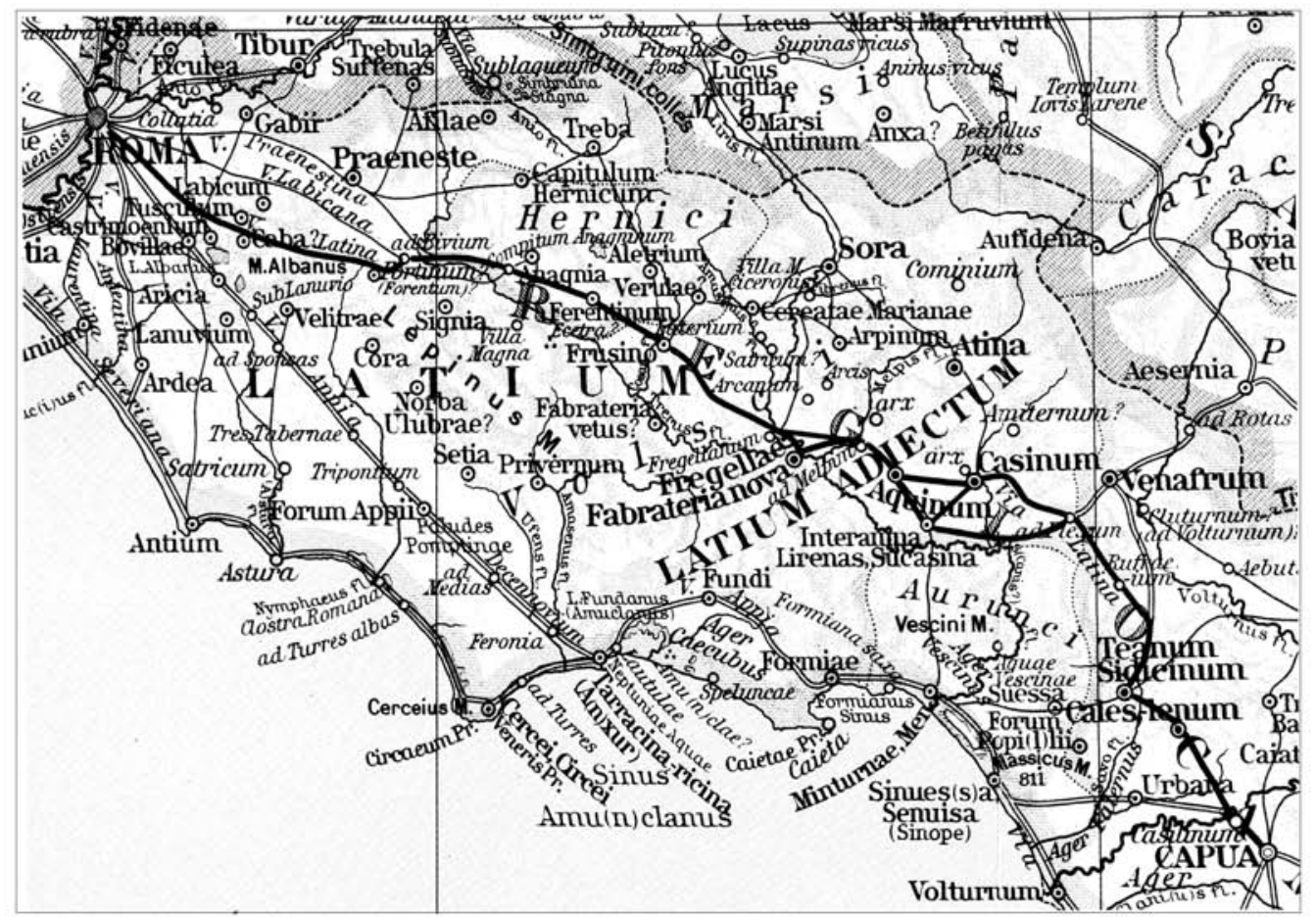

Figura 1. Mapa del Lacio Antiguo (reproducido de MONTI 1995)

recientemente excavadas en Fregellae un punto de referencia obligado ${ }^{1}$. Sin embargo, el complejo fregelano, a pesar de su manifiesta importancia y la riqueza de sus restos, resulta aún poco conocido, si bien algunas noticias sobre el edificio han sido ya dadas a conocer por Filippo Coarelli y breves referencias, acompañadas de algunas fotografías, aparecieron en los estudios de Alberto Ribera i Lacomba sobre las termas de L'Almoina. Los trabajos de excavación del complejo fregelano, emprendidos en el año 1996, acaban de finalizar (2001) y la publicación definitiva de los resultados se encuentra aún en fase de preparación. El presente artículo aporta una serie de datos inéditos sobre estas termas ${ }^{2}$ y su contexto cultural, con el fín de contribuir a la difusión de su conocimiento.

En efecto, los hallazgos de Fregellae introducen parámetros absolutamente nuevos en el estudio de los orígenes y evolució de la arquitectura termal romana, aportando numerosos y novedosos datos sobre otros aspectos -técnicos, artísticos, sociales y culturales- del mundo romano-itálico de los siglos III y II a. C. Datos, que permiten despejar múltiples incógnitas y corregir tópicos de la historia arquitectónica y cultural del

1. En las inmediaciones de Ceprano, aunque en el T. M. de Arce, Provincia de Frosinone. La musealización del edificio, en el marco del Proyecto del parco Archeologico di Fregellae, ha finalizado y su inauguración está prevista para principios del verano de 2002.

2. La realización de la planimetría se debe a un equipo de fenómeno balnear, invitando a replantear desde los fundamentos muchas cuestiones, a menudo dadas por superadas.

El complejo termal de Fregellae se suma a la amplia serie de hallazgos espectaculares que ha proporcionado la excavación de esta ciudad durante las últimas dos décadas. Fregellae, colonia latina del Lacio meridional, fue fundada en el año 328 a.C. como cabeza de puente romano en la orilla izquierda del río Liris, en pleno territorio bajo control oficial samnita (fig. 1). Tras sufrir los devastadores efectos de la II Guerra Samnítica, fue finalmente ocupada en torno al 320 a.C. y sus habitantes fueron masacrados. Sin embargo, poco después, en el año 313 a.C., el nuevo clima político-militar favorable a Roma permitió la refundación de la colonia, que pronto se convirtió en punto de referencia obligada para todo el valle medio del Liris, alcanzando progresivamente un protagonismo de primer orden en el contexto político romano, que fue violentamente truncado por la misma Roma con la destrucción total de la ciudad, en el año 125 a.C., como consecuencia de su célebre rebelión ${ }^{3}$.

El complejo termal de Fregellae se inserta en

varios arqueólogos. Las propuestas de reconstrucción son del autor, que asume toda responsabilidad al respecto.

3. Sobre la historia de Fregellae, véanse COLASANTI 1906 y, sobre todo, CoARELli 1998, 19 ss., con exhaustiva recopilación de las fuentes literarias. 


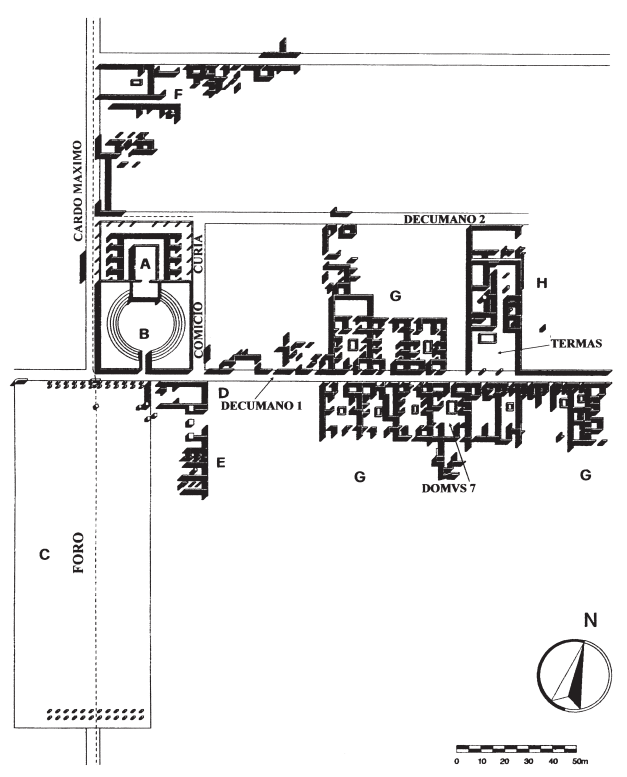

Figura 2. Fregellae. Situación de las termas (según COARELLI 1998)

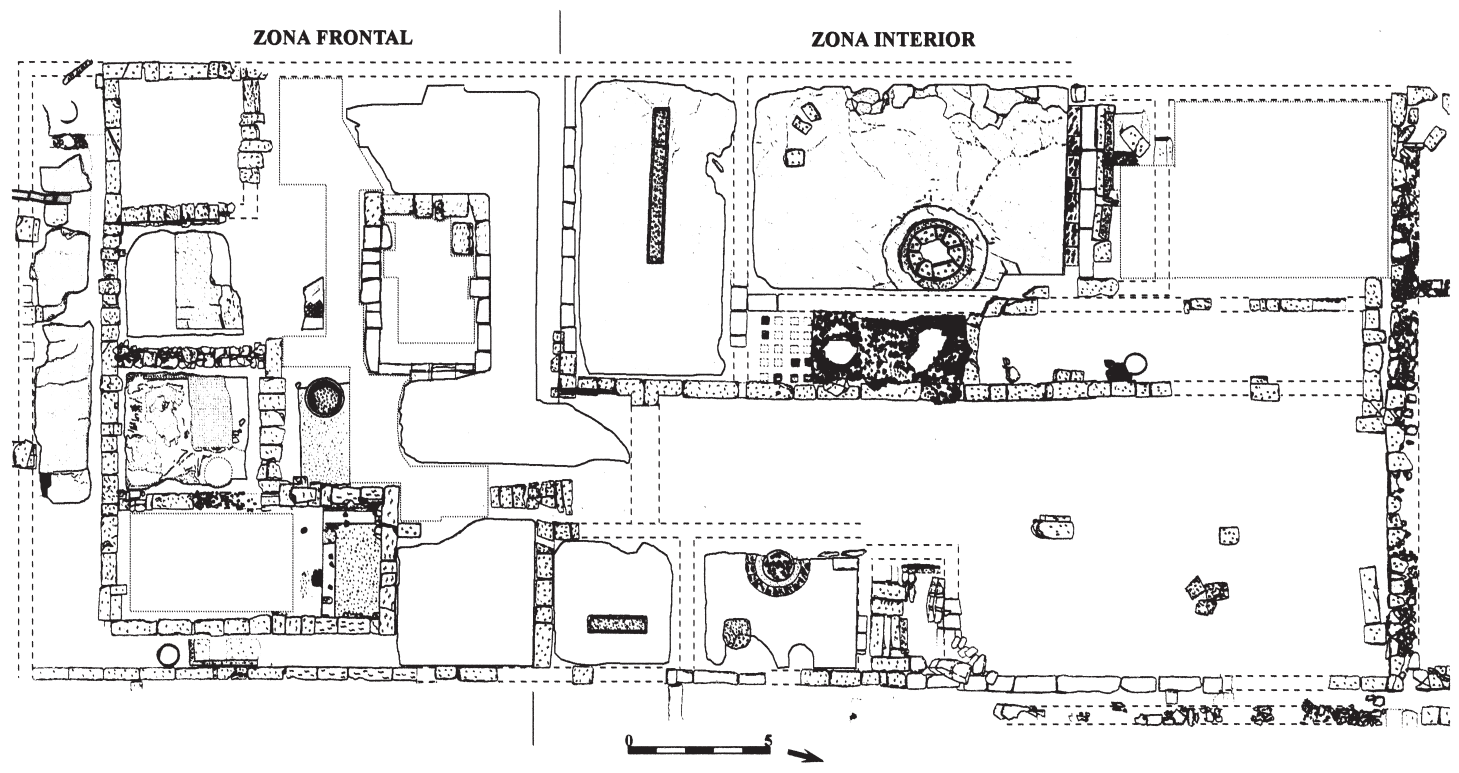

Figura 3. Fregellae. Planimetría de las termas (estado en el año 2000)

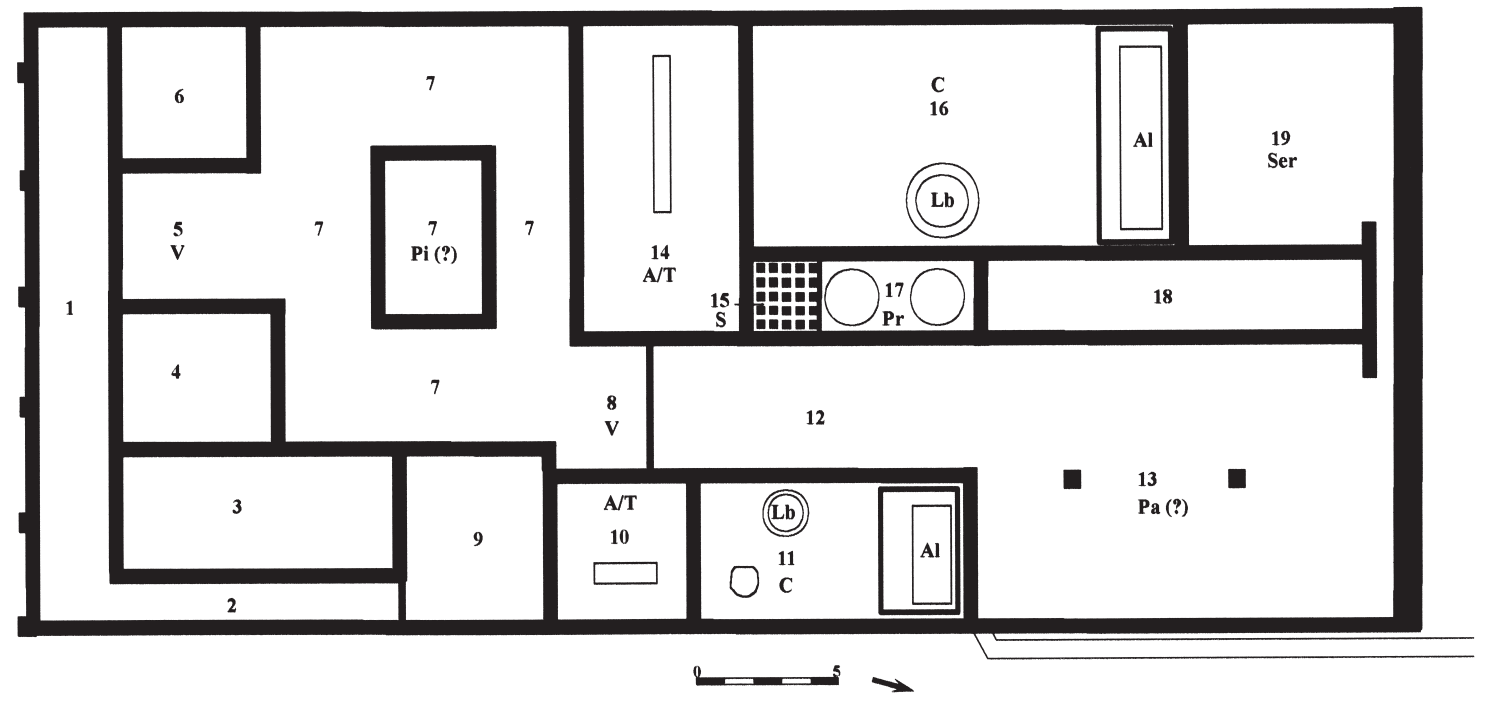

Figura 4. Reconstrucción planimétrica (II fase) 
el entramado urbano ocupando un área de $48 \mathrm{x}$ $22 \mathrm{~m}$. $\left(1056 \mathrm{~m}^{2}\right)$ de un sector residencial próximo al foro (fig. 2). La existencia de un edificio termal de uso público se había intuido ya desde 1987, gracias al hallazgo de una tessera ósea con la inscripción del nombre T. Atin(ius) Mem(mianus?) en uno de sus lados y la palabra bali(nea?), en el lado opuesto ${ }^{4}$. El edificio, tal y como se presentaba en el momento de su abandono en el año 125 a.C., conformaba una construcción unitaria y homogénea (figs. 3 y 4). Su frente se sitúa al sur, donde se encuentra una zona de 19 × $22 \mathrm{~m}$. (418 $\mathrm{m}^{2}$ ), que comprende varios espacios y estancias, accesible directamente desde el decumanus 1. Al norte de esta zona, ya en la parte interior del conjunto, se localizan las salas de baño más características, algunas estancias de servicio y un espacio con columnas, ocupando en total un área de 29 × $22 \mathrm{~m}$. $\left(638 \mathrm{~m}^{2}\right)$. Aún más al norte, se desarolla otro espacio rectangular, de 15 x 22 (330 $\left.\mathrm{m}^{2}\right) \mathrm{m}$., con pocos restos de construcción en su interior, que se extiende hasta el decumanus 2 , sin que, de momento, se haya podido establecer su eventual pertenencia a las termas.

Esta configuración del edificio es el resultado de una profunda reorganización y reconstrucción del solar durante una segunda etapa constructiva (II fase), que se remonta a la primera mitad del siglo II a.C. De hecho, la excavación en profundidad, por el momento limitada a toda la zona frontal, ha revelado la existencia de una fase anterior, del siglo III a.C., que también pertenece a un edificio termal de características monumentales. El edificio de I fase, localizado en un nivel sensiblemente inferior con respecto a la rasante de II fase, es igualmente de alta calidad. Había sido totalmente amortizado antes de la construcción del nuevo edificio, que, si bien mantendría las mismas funciones termales y las mismas dimensiones, al menos en la parte investigada, no ha respetado la distribución de los espacios del edificio anterior.

\section{DESCRIPCIÓN. ZONA FRONTAL (SUR)}

\section{a) II fase}

La zona frontal del edificio de II fase había sido objeto de profundas alteraciones ya desde época antigua, debido a intervenciones de expoliación del material constructivo. Sin embargo, pese a las pérdidas, ha llegado hasta nosotros todo el tercio septentrional de la zona, así como restos significativos de la cimentación del edifi-

4. Sironen 1990; creo, que no se puede descartar que $T$. Atinius fuese el propietario del balineum (-a/ae) de Fregellae: cfr. la breve discusión de los sistemas de pago cio, que permiten reconstruir su planimetría en esta zona. Más difícil resulta, en cambio, la interpretación de los distintos espacios, ya que a la pérdida de datos esenciales para su comprensión se añade la práctica inexistencia de paralelos contemporáneos en el contexto balnear itálico.

Esta zona está ocupada por al menos ocho ambientes. Los niveles excavados se encontraban en su mayoría por debajo de la cota pavimental de la II fase, conservada in situ sólo en el tercio septentrional del área, y pertenecían, casi exclusivamente, a un imponente relleno artificial, que cubría los restos de la I fase. Por medio de este relleno, de potencia superior a 2,00 m. y extendido en toda la zona frontal del edificio, se había realzado considerablemente la rasante del edificio de la II fase con respecto a la de su antecesor. Los cimientos de los muros de la II fase, realizados con grandes bloques de piedra caliza toscamente labrados $\mathrm{y}$, esporádicamente, con sillares de toba o, incluso, en mampostería, bien, descansan directamente sobre los pavimentos de la I fase, bien, cortan dichos pavimentos buscando el firme.

El primero de los ambientes (1) de la zona frontal se extiende a lo largo del decumanus $1 \mathrm{y}$ ocupa todo el frente del edificio. Se trata de un pórtico $(20,80$ x 2,80 m.) del que se conservan restos de la cimentación del muro de fondo, los cimientos de dos columnas y las fosas de cimentación de otras más. En cambio, han desaparecido por completo los alzados, la pavimentación y gran parte de la cimentación, debido a la expoliación, especialmente agresiva en esta zona.

A las espaldas del pórtico se alinean cinco ambientes, siendo el más oriental muy estrecho y alargado. Uno de ellos, el ambiente 5 (4,60 x 4,40 m.), carece de muro de cierre en su lado septentrional, abriéndose directamente al amplio espacio 7. A ambos costados del ambiente se sitúan sendas estancias, de dimensiones similares: el ambiente 6 (4,20 x 4,60 m.), al oeste, y el ambiente $4(5,10 \times 4,50 \mathrm{~m}$.), al este. Contiguo a este último se desarrolla el gran ambiente rectangular alargado $3(9,40 \times 3,90 \mathrm{~m})$. Entre este último ambiente y el muro perimetral de las termas se ubica un espacio estrecho y muy largo, con aspecto de corredor $(9,40 \times 1,10 \mathrm{~m}$.).

$\mathrm{Al}$ norte de los ambientes 4,5 y 6 , se abre lo que parece ser un gran espacio rectangular (7), de $14,60 \times 10,80$ m., sin divisiones internas apreciables y con un apéndice de 4,30 x 3,20 m. en su

de entrada a los baños y el uso de teselas en NiELSEN 1990, 131 ss. (en especial 134). 
esquina noreste (8). El espacio 7 se caracteriza por la presencia en su centro de los cimientos en grandes sillares de una estructura rectangular $(5,40 \times 3,40$ en el interior de los sillares), directamente apoyados sobre el pavimento de I fase. El espacio 7 conservaba parte de su pavimentación en opus signinum en su mitad norte. Alrededor de la estructura rectangular, al menos en sus lados norte y este, corría un borde ancho y ligeramente realzado de opus signinum, con decoración de gruesas teselas cúbicas de toba y cerámica, de distintas tonalidades cromáticas, colocadas a la manera del opus tessellatum. En cambio, en la parte meridional de la estructura rectangular el pavimento se ha perdido y la secuencia estratigráfica estaba alterada. El espacio 7 comunicaba hacia el sur con el ambiente $5 \mathrm{y}$, hacia el norte, con la zona interior de las termas por medio del ambiente 8 . Precisamente, en el lado norte de este último se conservan elementos para el anclaje de la puerta que permitía el acceso al ambiente 12 . No se han encontrado indicios de otros huecos de comunicación con las estancias contiguas.

Al este del espacio 7 se sitúa el ambiente 9, de planta casi cuadrada $(5,10 \times 4,80 \mathrm{~m}$.) y con el suelo revestido de opus signinum decorado con teselas blancas. La expoliación parcial de sus cimientos ha borrado toda huella de los huecos de comunicación con los ámbitos circundantes, si bien uno de ellos debería situarse en la esquina sureste de la estancia, garantizando la comunicación con el corredor 2 y, a través de éste, con el pórtico de la fachada del edificio y el decumanus. Al parecer, el ambiente 9 estaba abierto también hacia el espacio 7 .

\section{b) I fase}

Como ya se ha dicho líneas arriba, todos los cimientos de la II fase descansan a unos dos metros por debajo del nivel pavimental de la misma, donde se encuentran los restos de un edificio, que se remonta a una fase anterior. La excavación de este último acaba de finalizar (año 2001) y su estudio se encuentra aún en fase incipiente. Sus muros habían sido expoliados en su totalidad, antes de la nueva organización de la zona y el realce de la rasante mediante rellenos. Los pavimentos, en cambio, de gran variedad y muy buena calidad, se han conservado en muchos puntos. Se puede adelantar que en este edificio de la I fase son reconocibles varias estancias relacionadas con la práctica del baño.

Así, en la zona oriental se han conservado parcialmente las trazas de al menos tres estancias alineadas en sentido norte-sur. Una de ellas, pavimentada con losetas cerámicas rojizas en forma de escamas colocadas sobre un lecho de mortero hidráulico, contaba con un banco fijo, construido contra su pared meridional y, probablemente, con un labrum sobre pedestal (por la impronta en el suelo). El ambiente más septentrional, situado en una cota más baja, también presenta solado de losetas cerámicas. En cambio, el ambiente meridional, bajo cuya rasante pasa un canal de desagüe, apenas conserva restos de pavimentación.

En la parte central, de más difícil reconstrucción, se perciben algunas subdivisiones, que invitan a reconocer varias estancias, dotadas de pavimentos de distintos tipos. En la parte más próxima al decumanus predomina un espacio con pavimentación en opus signinum, decorado con teselas blancas, probablemente con divisiones internas. Más hacia el norte se localizan uno o dos ambientes más, uno de ellos con impronta circular en el suelo, indicativa de la posición del pedestal de un labrum. Aún más al norte parecen poder distinguirse dos ámbitos más, pavimentados con diferentes tipos de opus figlinum. El más oriental está revestido con losetas y conserva en su interior un labrum de piedra caliza, apoyado directamente sobre el pavimento y transformado en un curioso artilugio, quizás relacionado con la calefacción de la estancia. Contigua a estos ambientes, en el extremo norte de la zona de I fase excavada, apareció una gran sala dotada de un alveus colectivo, en su lado occidental, y pavimentada con losetas polícromas en forma de escamas. Una franja de placas de piedra negra volcánica, seguida de otra de losetas polícromas romboidales, marcan el borde del alveus. Este último, realizado en opus signinum sobre un núcleo de opus testaceum, cuenta con pluteum decorado con teselas de piedra caliza, y gradus inferior / pulvinus. Bajo el alveus, en el subsuelo, se desarrolla un gran conducto de calefacción, que se prolonga hacia el sur bajo el suelo pavimentado de la estancia contigua. El horno se encontraba seguramente al norte de la estancia, en la zona no excavada por estar situada bajo pavimentos conservados de la II fase. El dispositivo se presenta como un amplio canal abovedado de opus testaceum, con su fondo revestido de baldosas cerámicas y la bóveda realizada mediante arquillos adosados, construidos con minúsculas dovelas cerámicas (9 cúneos por arco).

Entre los materiales empleados en los cimientos de la II fase destacan algunos sillares reutilizados, así como varios fragmentos de un tipo especial de dovelas cerámicas, muy diferentes a las utilizadas en la bóveda del conducto de calefacción del alveus, pertenecientes a una gran bóveda en opus figlinum. Varios de estos frag- 


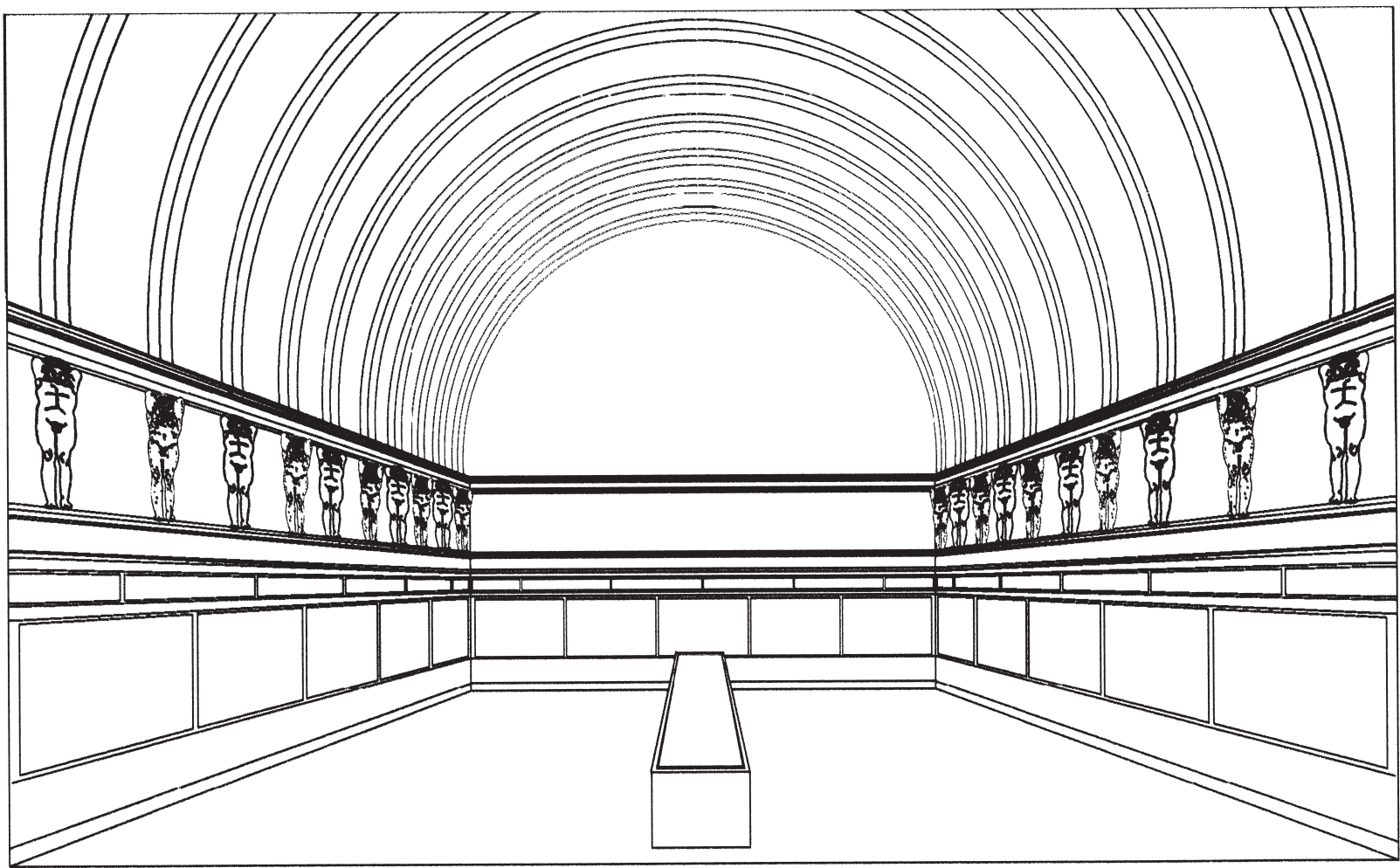

Figura 5. Reconstrucción del aprodyterium/tepidarium (ámbito 14)

mentos habían sido aprovechados para calzar los sillares de los cimientos de la II fase y otros entre los mampuestos de la misma cimentación, por lo que su pertenencia al edificio de la I fase es segura. En consecuencia, al menos una de las estancias de la I fase estaba abovedada.

\section{DESCRIPCIÓN. ZONA INTERIOR (NORTE)}

En la zona interior sólo se ha excavado la II fase del edificio. La zona balnear propiamente dicha consta de dos sectores termales bien definidos (occidental y oriental), formados por varias salas cada uno. El espacio alargado $12(10,40 \mathrm{x}$ 4,50 m.), al que se accede desde la zona frontal atravesando el ambiente 8 , parece desempeñar el papel de elemento de separación entre sectores, si bien podría pertenecer a uno de estos. De su pavimentación apenas se conserva in situ una pequeña porción de tejas fragmentadas colocadas de canto sin regularidad. Al norte del ambiente 12, extendiéndose también por todo el área a las espaldas del sector oriental, se encuentra el espacio rectangular 13 (14,60 x 9,60 m.), situado a una cota superior. En este espacio, alineados con el muro que separa el ambiente 12 del sector oriental, se encuentran in situ los plintos de dos columnas, que indican la existencia de un pórtico o de un construcción hipóstila. Dos plintos más y restos de fustes de columnas se han encontrado en el interior del área, algunos reuti- lizados en la construcción del muro de cierre septentrional del conjunto termal. Precisamente, este último muro presenta características muy diferentes del resto de los muros de las termas, al estar realizado en fábrica poligonal y superar en anchura los 1,10 m. Su papel de muro de contención de la terraza situada más hacia el norte, cuya eventual pertenencia al edificio termal no se ha podido establecer aún, explica la solidez y el opus empleado. Este muro se remonta probablemente a la II fase constructiva de las termas o a una reforma posterior, como indican los restos de columna reutilizados como material de construcción, así como el hecho de que el muro poligonal se asiente sobre otro muro anterior realizado en sillares de toba.

Como ya se ha dicho, a ambos lados del ambiente 12 se ubican sendos sectores termales, independientes el uno del otro. El sector occidental es el más amplio, sofisticado y monumental. Consta de dos grandes salas (14 y 16) y de un ámbito más pequeño (15), así como de un horno (17), con su correspondiente espacio semi-subterráneo de servicio (18) y de un espacio auxiliar situado junto a la esquina noroeste del sector (19). En cambio, el sector oriental consta de dos salas para el baño (10 y 11), que reproducen en menor escala las dos salas principales del sector opuesto, y, probablemente, por el ámbito (9), que se desarrolla hacia la zona frontal del conjunto. 
De los muros perimetrales y divisorios de las distintas estancias de ambos sectores se conserva la cimentación, de $0,60 \mathrm{~m}$. de ancho, muy sólida al estar realizada por lo general con sillares bien labrados de piedra caliza y, esporádicamente, de toba. Se conservan importantes restos de los pavimentos de los principales ámbitos, así como algunas estructuras pertenecientes al mobiliario fijo de las estancias de baño y del sistema de calefacción.

\section{a) Sector occidental}

El primer ambiente claramente perteneciente al sector occidental es la espaciosa sala rectangular $14(10,50 \times 5,50 \mathrm{~m}$.), orientada en dirección este-oeste. La desaparición de los alzados e, incluso, de una buena parte de la cimentación, no permite localizar los huecos de transición a la estancia. No obstante, la posición de esta sala con respecto al resto de estancias y espacios, sugiere la existencia de un hueco de acceso en su lado corto occidental, así como de uno o dos huecos más en su costado septentrional, para facilitar la comunicación con los ámbitos $15 \mathrm{y}$, sobre todo 16. El suelo está revestido con un delicado pavimento de opus tessellatum, realizado con minusculas teselas calizas de color blanco hueso, del que se conservan restos importantes, así como toda la preparación. Sobre el eje este-oeste de la sala se desarrolla un banco alargado (sedes), realizado con sillares de piedra caliza y revestido de opus signinum, que presenta el interior de la cara superior ligeramente rebajado. Como se verá más adelante, esta estancia estaba probablemente cubierta por la impresionante bóveda de opus figlinum, revestida con estuco liso de color blanco hueso y sustentada por telamones exentos de terracota, con función decorativa (fig. 5).

El segundo ámbito de este sector es una pequeña estancia casi cuadrada (15), de 2,50 x 2,40 m., encastrada entre las salas 14 y 15, el ambiente 12 , y el horno (17). No se han conservado in situ restos del alzado, ni de la pavimentación de este ámbito. Tampoco la cimentación de sus muros proporciona datos sobre la posición de eventuales huecos de acceso. No obstante, es posible que de su pavimentación procedan algunos fragmentos de bipedales revestidas de una gruesa capa de opus signinum, encontrados en el entorno. El subsuelo del ámbito alberga, sorprendentemente, un hypocaustum "canónico". Del hypocaustum se conservan in situ restos considerables de 4 x 5 filas de pilae, realizadas con baldosas o tegulae recortadas de modo que forman elementos cuadrados besales y dispuestas a intervalos regulares. Las pilae descansan sobre un área realizada con grandes y gruesas baldosas. La comunicación del hypocaustum con el horno se efectuaba a través de una amplia desembocadura rectangular (praefurnium). En el interior del hypocaustum, sobre todo junto al horno, se encontraron numerosos fragmentos de tubos cilíndricos de barro, de seis centímetros de diámetro y de longitud indeterminada, descolocados de su posición original. Algunos de estos fragmentos presentan ramificaciones laterales, un detalle que podría sugerir su pertenencia a un sistema de circulación de los gases desde el hypocaustum hacia el alzado de la estancia.

El tercer ámbito del sector occidental es la espaciosa sala rectangular $16(14,80 \times 7,40 \mathrm{~m}$. o $109,52 \mathrm{~m}^{2}$; relación 2:1). Está dotada de un gran alveus, que ocupa casi todo su lado corto septentrional, así como de un pedestal cilíndrico exento $(\varnothing 1,80 \mathrm{~m}$.) situado contra la pared oriental de la estancia. Este soporte, realizado con piedra caliza en forma de dovelas colocadas horizontalmente y recubiertas en su cara exterior de opus signinum decorado con teselas blancas, se ha conservado íntegro. En origen servía de apoyo a un gran labrum, como demuestra, además de su tipología, la concavidad que forman las dovelas en su parte superior para recibir dicho recipiente. El alveus, recubierto por una gruesa capa de opus signinum con acabado muy cuidado, se desarrolla, en su parte conservada, bajo rasante, a excepción de la parte superior del respaldo del asiento longitudinal que recorre su lado norte. Se accedía desde la sala bajando el único escalón que forma el borde meridional de la bañera, situado al mismo nivel que el suelo de la estancia. No obstante, la presencia en el suelo de una impronta longitudinal, con giro hacia el costado lateral de la estructura, indica la posición del parapeto frontal del alveus (pluteus), que sobresalía por encima de la rasante hasta una altura no determinada, pero seguramente la justa como para no impedir el acceso cómodo al escalón mencionado. En su interior, la presencia de al menos dos muretes transversales de tejas fragmentadas cogidas y recubiertas con argamasa hidráulica, que cortan el gradus, indica que, en algún momento posterior a su construcción, la bañera había sido dividida en al menos tres compartimentos.

La sala presenta una pavimentación en opus tessellatum de color blanco, parcialmente conservada, idéntica a la de la estancia 14. En la zona delante del alveus, una impronta longitudinal advierte sobre la existencia de una cenefa de lastras de piedra negra volcánica, totalmente expoliada. El mismo tipo de borde parece que circundaba la base del pedestal, como demuestran la impronta circular en el pavimento y la comparación con el caso análogo de la sala 11 del sector oriental. A lo largo del frente del alveus, entre la 
cenefa y el pavimento, corre otro reborde de lastras rectangulares cuidadosamente pulimentadas. En la esquina suroeste del ambiente, tres sillares, uno de ellos in situ, parecen indicar la presencia de un banco. En cuanto a los accesos de la estancia, no se han conservado restos que permitan intuir la posición de las puertas, si bien cabe esperar un hueco de comunicación con la sala contigua 14 y, quizás, otro de acceso a la pequeña sala 15.

$\mathrm{Al}$ norte de esta estancia se localiza otra (19), de planta cuadrada $(7,50 \times 7,50 \mathrm{~m}$.). Su posición, la falta de pavimentación y otras características indican que se trataba, probablemente de un espacio de servicio.

Paralelo al costado oriental de las estancias 16 y 19 se sitúa el compartimento de alimentación y limpieza del horno (18), ámbito alargado (13,60 x $2,40 \mathrm{~m}$.) y en parte subterráneo. El horno (17), situado en el extremo sur de ámbito, es de doble cámara y está cuidadosamente construido con grandes fragmentos de tegulae $(5,80 \times 2,40 \mathrm{~m}$.). Inmediatamente al este de estas estructuras se localiza el ya mencionado ambiente 12 y el espacio 13 .

\section{b) Sector oriental}

El sector oriental es de dimensiones mucho más reducidas. Consta de las estancias 10 y 11 y es casi una réplica del sector anterior, si bien carece de instalaciones de calefacción fijas.

El ambiente más meridional 10 es de planta prácticamente cuadrada $(4,40 \quad \mathrm{x} \quad 4,30 \quad \mathrm{~m}$.). Presenta un pavimento en opus signinum decorado con teselas blancas de piedra caliza. En posición central se desarrolla un banco alargado, con la cara superior ligeramente cóncava, también recubierto de opus signinum, sin decoración. Como en los demás casos, no se conservan indicios en relación con los accesos de la estancia debido a la expoliación de los muros perimetrales. No obstante, cabría esperar una vía de acceso, bien desde el ambiente contiguo 9 (menos probable que desde el vestíbulo 8 ), bien desde el ambiente 12, y seguramente estaba comunicado con la sala 11.

La sala 11, de planta rectangular de 8,90 x 4,80 m., está dotada de un alveus, en su lado septentrional, realizado con sillares de piedra caliza recubiertas de opus signinum, que se desarrolla bajo rasante a excepción de la parte superior del respaldo. En algunos puntos del respaldo se conservan exiguos restos de decoración en opus tessellatum, con empleo de teselas blancas y negras. Un pedestal cilíndrico para el apoyo de un labrum, parcialmente conservado, se sitúa contra el muro occidental. Está realizado con pequeños mampuestos cogidos con mortero de barro y recubierto por una gruesa capa de opus signinum.
Junto a la esquina sureste de la sala se encuentra un elemento (¿banco?) de forma casi cuadrada, con las esquinas redondeadas y recubierto de opus signinum. El pavimento del ambiente presenta un revestimiento de opus signinum, decorado con una gruesa cenefa de meandros realizados con teselas blancas. La base del pedestal cilíndrico está rodeada por una franja anular de opus signinum decorado con teselas, seguida por otra, de lastras de piedra volcánica negra, con incisiones en forma de espina de pez en la superficie. Una cenefa del mismo material y con incisiones idénticas bordea el pavimento en el lado septentrional de la estancia, delante del alveus, así como a lo largo de un breve tramo de su lado occidental.

A las espaldas del alveus, algunos sillares de toba conservan huellas de un specus, orientado este-oeste, perteneciente con toda probabilidad al sistema de abastecimiento hídrico de las termas. Se trata probablemnete de una conducción que, procedente de la zona al norte de las termas, corre paralela al flanco exterior del edificio, al que penetra junto a la esquina sureste del ámbito 13, efectuando una inflexión de 90 grados por medio de un breve tramo achaflanado. Sus huellas en el exterior de las termas se reducen en los restos de un endeble murete de mampostería.

\section{INTERPRETACIÓN}

El conjunto termal de la II fase se presenta como una edificación monumental, caracterizada por la duplicidad de sus espacios, al estar integrada por dos sectores termales, occidental y oriental, de desigual rango. En el estado actual de la investigación, no se puede aún afirmar si el arquitecto se inspiró en los parámetros organizativos del edificio de la I fase. Queda patente, sin embargo, su esfuerzo de crear un centro balnear bien articulado y dotado de la infraestructura tecnológica más puntera de la época.

La lectura arquitectónica y funcional del complejo de la II fase plantea ciertas dificultades, debidas, sobre todo, a la escasa información que aportan los restos con respecto a los huecos de comunicación entre los distintos ambientes. Esta información habría facilitado, sin duda, la reconstrucción de los recorridos y, en consecuencia, habría ayudado a elucidar las funciones precisas de cada espacio y estancia, sin necesidad de recurrir a una interpretación basada en modelos teóricos, a menudo muy arriesgados. En cambio, la notable homogeneidad del edificio, que revela la existencia previa de un proyecto arquitectónico bien razonado, contribuye a interpretar con cierta seguridad la mayoría de sus componentes. 
Por cuanto se deduce del análisis arquitectónico, los accesos principales del edificio se encontraban al sur, donde se erigía la fachada monumental sobre el decumanus 1. La fachada consistía probablemente en la columnata de un pórtico (1), compuesta por un número indeterminado de columnas de orden desconocido. En el muro de fondo de este espacio alargado debían abrirse dos o más vanos de comunicación con las estancias situadas a sus espaldas. Una de estas aperturas se percibe en el extremo oriental, facilitando el tránsito al ámbito 2. El ingreso principal parece que ocupaba una posición axial con respecto a la zona más noble del edificio, dando acceso al ambiente 5 , cuyas características invitan a interpretarlo como vestíbulo. El acceso a las dos estancias 4 y 6 que lo jalonan podría efectuarse, bien desde este último ambiente, bien desde el gran espacio 7 al que se pasa atravesando el vestíbulo. La función de las dos estancias 4 y 6 no se ha podido determinar con seguridad, aunque parece poco probable que fuesen tabernae. Con respecto al ambiente 6 , algunos indicios relacionados con la presencia de canalizaciones de barro en su entorno harían pensar a su posible uso como latrina, aunque la hipótesis es débil. El ambiente 4, vista su posición, podría haber desempeñado funciones de depósito de utensilios, de local administrativo del balneator, o de ambas, si bien carecemos de datos suficientes para su interpretación. Las mismas dificultades plantea el ambiente 3. En todo caso, los ambientes 3,4 y 6 resultan bastante alejados de la zona de las salas calientes, situadas más al norte, como para intentar atribuirles funciones relacionadas directamente con la práctica del baño stricto sensu. No obstante, habida cuenta de la antigüedad, originalidad y monumentalidad del edificio fregelano, ninguna hipótesis puede ser descartada de momento.

El espacio rectangular 7, que se abre al norte del vestíbulo 3, presenta una serie de características aún no esclarecidas del todo. Como demuestran los restos conservados, al menos dos terceras partes del suelo de este espacio, estaba revestido de opus signinum, rodeando una gran estructura rectangular cuyo perímetro estaba marcado por

5. Sobre este tipo de pozos fregelanos, obtenidos por susperposición de elementos anulares de barro de gran diámetro, véase MonTI 1994. Sin embargo, el mismo sistema se documenta también en relación con la evacuación de agua, por ejemplo en otras habitaciones de este mismo edificio termal.

6. En las proximidades de la estructura se ha encontrado un fragmento de columna acanalada, de diámetro reducido. Así mismo, la pavimentación del espacio 7 parece implicar la existencia de cubierta.

7. No parece, que esta eventual estructura hidráulica fuese una cisterna. En ninguna de las domus de un borde ligeramente realzado y cuidadosamente decorado con un peculiar opus tessellatum. Los pavimentos conservados del espacio 7 habían sufrido amplios cortes, que se asocian a una reforma posterior, al parecer relacionada con el sistema de acometida de agua y de alcantarillado.

Los restos de los imponentes cimientos de la estructura rectangular, que domina el centro del espacio 7, están asentados directamente sobre el pavimento de I fase, en correspondencia con el antiguo caldarium y su alveus. Su robustez pone de manifiesto su función de soportar grandes cargas o presiones. En el interior de la estructura, muy revuelto y carente de las hiladas superiores de los sillares, no se encontraron in situ restos de revestimientos pavimentales o parietales. Con estas premisas podría parecer difícil asociar la estructura rectangular con algún tipo de construcción hidráulica de tipo fuente / ninfeo o de piscina / ко $\nu \nu \mu \beta \eta \tilde{\theta} \rho \alpha$, si bien dicha posibilidad no se puede excluir del todo, puesto que la expoliación de los sillares pudo haber borrado completamente las huellas de eventuales revestimientos e incluso del fondo de un dispositivo semejante. Otro problema en relación con la interpretación de la estructura y del espacio 7, en general, se haya en la desastrosa situación de la secuencia estratigráfica al sur del rectángulo. Sin embargo, en el interior de la estructura, en su esquina sureste y cortando el pavimento de I fase, se documentó un conducto o pozo de barro de gran diámetro, al parecer destinado a la evacuación de agua ${ }^{5}$.

Una interpretación plausible podría hallarse explicando la estructura rectangular como cimiento de las columnas de un peristilo ${ }^{6}$, con independencia de las características, incluidas las eventuales funciones hidráulicas, del espacio ceñido entre las columnas. Por medio de un espacio con peristilo central se lograría una notable cohesión entre los ambientes frontales y los interiores del conjunto termal. Sin embargo, como se ha aludido líneas arriba, no se puede descartar, que, a pesar de la falta de restos in situ, hubiese alguna estructura hidráulica en el interior del rectángulo ${ }^{7}$. De hecho, las piscinas para

Fregellae se ha encontrado un dispositivo semejante bajo los impluvia, al contrario que en otras ciudades, como, por ejemplo, Pompeya. La razón de esta ausencia de depósitos podría explicarse por la existencia de un acueducto urbano, documentado en algunos puntos de la ciudad, en especial, en el foro, donde se conservan restos imponentes (DE ALBENTIS 1990, 141: Monti 1994; CoArelli 1998, 56). Una ramificación de este acueducto se podría, quizás, reconocer en los restos de canalizaciones documentadas a lo largo del costado oriental de las termas. 


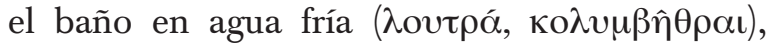
comunes en los baños griegos, encuentra un paralelo en el loutron de las Termas Estabianas, existente ya desde el período I de Eschebach. Hacia principios del siglo II a.C. (o, incluso, antes), la asociación de una piscina (con peristilio) con un $\beta \alpha \lambda \alpha v \varepsilon i ̂$ bien definida, por ejemplo, en Mesene ${ }^{8}$. Algo posterior es el $\beta \alpha \lambda \alpha v \varepsilon i ̂ v$ de Tesalónica, junto al ágora, que combina la tholos dotada de bañeras

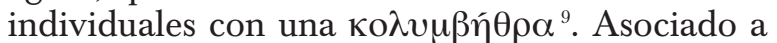
una palestra, está, en cambio, el conjunto denominado Grandes Baños del palacio de Pela, dota-

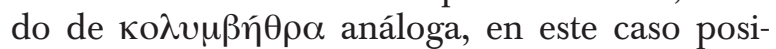
blemente cubierta ${ }^{10}$, reproduciendo el esquema tradicional. Esta relación se hace patente en las termas de L'Almoina, donde un loutron (piscina, lacus), perfectamente análogo al de Pompeya y a las ко $\lambda v \mu \beta \hat{\eta} \theta \rho \alpha \iota$ griegas, está incluida en el espacio sagrado adyacente a las termas ${ }^{11}$. También las grandes estructuras conocidas como piscinae, que se documentan en Italia a partir de finales del siglo IV a.C., guardan relación con prácticas de baño. La piscina Publica de Roma, construida tras la ejecución de la Aqua Appia (312 a.C.) desempeñaba, con toda probabilidad, un papel importante en los ritos de Fortuna ${ }^{12}$. Otra estructura análoga y del mismo período es la de Paestum $^{13}$. No hay que olvidar, como a menudo ocurre, que durante las décadas finales del siglo II a.C. se documenta un lacus balinearius en Aletrium, muy cerca de Fregellae ${ }^{14}$. No sorpren-

8. Breve descripción en THÉmelis 1999, 90 s. La cronología del edificio oscila entre finales del siglo IV y principios del siglo II a. C.

9. Cfr. BlaCKMAN 2001, 83 (AEMTH 11, 351-364).

10. Chrisostomou 1996; 1998; Misailidou DESPOTIDOU 1998; en este complejo no se han detectado instlaciones de calefacción.

11. En último lugar, Marín-Ribera 2000, 154 s. En Cabrera del Mar, donde se ha perdido gran parte de un espacio pavimentado al sureste del apodyterium, no se documentó un dispositivo análogo. En Baetulo, en cambio, una piscina aparece integrada en un ámbito, identificado como frigidarium.

12. Coarelli (CoARelli 1998, 299 ss.) piensa que la piscina Publica, situada fuera de la Porta Capena, pudo haber jugado un papel importante en los ritos de Fortuna Virilis (cfr. nota siguiente), antes de que Roma se dotara de balnea adecuados. Estos importantes ritos relacionados con los edificios de baños, especialmente con los calidaria, estaban aún vivos en época augustea, si bien Fortuna había sido suplantada por la versión, más helenizante, de Venus Verticordia: Ov. Fast. IV 133-164 (v. 146: calida qui locus umet aqua). Champeaux 1982, 375 ss.; Torelli 1984, 77 ss.; CoArelli 1988, 270 s., nota 51; 293 ss.; Almagro Gorbea-Álvarez 1993, 216 ss.; cfr. Pestalozza 1951, dería, por tanto, una estructura análoga también en Fregellae, englobada en el edifico termal ${ }^{15}$.

En la esquina noreste del espacio 7 se genera un ámbito rectangular, abierto hacia el sur y con restos de un acceso en su lado norte. Se trata seguramente de un vestíbulo que conduce al ambiente 12 y a las salas internas de los baños.

El ambiente 9, situado al este del espacio 7, presenta dificultades de interpretación, ya que no se han conservado indicios de sus accesos. No se puede descartar que comunicaba con el espacio 7, si bien, parece probable que fuese accesible desde el ambiente 2 (un corredor) y que servía de preámbulo a las estancias calientes del sector oriental. En efecto, la interpretación global del conjunto balnear implica una entrada separada para cada uno de los dos sectores de salas termales propiamente dichas, razón por la que el ámbito 2 puede ser interpretado como la vía de acceso al sector oriental, a través del ambiente 9 .

Las estancias 10 y 11 del sector oriental constituyen réplicas de las salas 14 y 16 del sector occidental y desempeñaban las mismas funciones. Sus dimensiones, menores en comparación con las salas del sector opuesto, invitan a reconocer en ellas el sector femenino de las termas. La identificación de la sala 11 con el caldarium de este sector queda patente por sus infraestructuras y sus analogías con la sala 16 del sector opuesto. La sala 10, al igual que la sala 14 del sector occidental, corresponde probablemente a un apodyterium,

397 ss.; GaGÉ 1958. Fotruna, en sus diferentes hipóstasis, es una divinidad del paso de edad, del crecimiento fisiológico masculino y femenino y también de ascensión social (GAGÉ 1958; CHAMPEAUX 1982, 423): tutela el ingreso de los jóvenes al cuerpo social y político y de las jóvenes a la madurez sexual, equivalente a la habilitación para el matrimonio ( $c f r$. CoArelli 1988, 270, s. y nota 51). Fotruna Barbata (que adultos barba induat; Aug. Civ. 4, 11) e Fortuna Virgo están vinculadas también a la iniciación al matrimonio (TORELli 1984, 84 s.; 89). El reflejo de la antigua función de Fortuna en relación con el cambio de status y la ascensión social se percibe en su hipóstasis de Fortuna Balnearis, venerada por la plebe y los esclavos.

13. Greco-Theodorescu 1987, que asocian tanto la estructura de Paestum como la de Roma con el culto de Fortuna.

14. Zevi 1976; CoARElli 1982, 196 s. La inscripción enumera las evergesías de L. Betilenus Varus. Otro lacus, se encontraba en las proximidades de una puerta ( $c f r$. los restos, seguramente de una cisterna, junto a la actual Porta San Pietro).

15. Sobre las características de este tipo de estructuras y sobre las diferencias entre piscina y natatio. NIELSEN 1990, 154, s. 
quizás con funciones también de tepidarium. A esta suposición conduce la aparente ausencia de un tercer ambiente susceptible de completar la teórica secuencia apodyterium/tepidarium/caldarium en el sector occidental, hecho que invita a ser prudentes a la hora de identificar los distintos ambientes de las termas de esta época a partir del esquema tripartito de baños posteriores. En efecto, la tripartición se podría proponer para el sector oriental (femenino) si se comprobara la relación del ambiente 9 con este sector y se le asignaran funciones de apodyterium. Aún así, sería sorprendente que el sector occidental, el más monumental, no presentase la misma distribución, a menos que no se interpretara como tercer elemento de la supuesta tripartición alguno de los espacios 7 y 12. Ante esta dificultad, parece más conveniente dejarnos guiar por el modelo del sector principal y sus dos grandes salas 14 y 16 .

Estas dos salas conforman, junto al pequeño ambiente con hipocausto (15) la zona interior del sector occidental (balneum virile). La monumentalidad del sector parece confirmar, que tanto el espacio 7, como los ambientes que lo preceden en dirección sur, estuviesen relacionados exclusivamente con el balneum virile.

La amplia sala 14 representa, con toda probabilidad, el punto de partida del itinerario a través de las estancias calientes. Su interpretación plantea ciertos problemas, puesto que cabría reconocer en ella tanto el apodyterium como el tepidarium del sector masculino. De hecho, este sector masculino parece carecer de una de las dos primeras estancias del esquema apodyterium, tepidarium y caldarium, que se manifiesta bien definido ya en los establecimientos del siglo II a.C. En efecto, de ser ciertas las interpretaciones de la investigación, el esquema está presente en Cabrera del Mar, Valencia y Musarna. En el balneum virile de Fregellae, en cambio, el único espacio conocido a través de la excavación que, por sus dimensiones y su posición, podría ajustarse a las características de un apodyterium o de un tepidarium es, como se ha señalado líneas arriba, el ámbito 12, que, sin embargo, no ha brindado, de momento, indicio alguno que permita tal interpretación. Con respecto a éste último ámbito, cabe recordar, que no han aparecido restos de su cierre septentrional, si bien la existencia en origen de una escalera, muro, o de otro elemento de contención que lo separase del espacio contiguo 13 se debe dar casi por descontada, visto el salto de cota entre sendos ámbitos. Entre otras muchas posibilida- des, el ámbito 12 podría haber desempeñado el papel de simple ámbito transitorio entre la zona frontal de las termas y el espacio 13 o de un espacio con cualquier otra función. Los exiguos restos de pavimentación de opus figlinum encontrados en su interior, que, en todo caso, contrastan con la homogeneidad de las pavimentaciones del resto de estancias del sector masculino (opus tessellatum blanco) y femenino (opus signinum decorado), no son suficientes para interpretar el ambiente como apodyterium, si bien su disposición con respecto a las demás estancias y al sistema de calefacción deja abierta esta posibilidad. Más difícil resulta atribuirle funciones de distribuidor para el acceso a las salas situadas a sus lados largos, ya que no es posible admitir que sirviese a ambos sectores a la vez.

Con toda probabilidad, la sala 14 estaba provista de una bóveda de opus figlinum, como indican los abundantes restos encontrados en su interior y la anchura de la estancia, compatible con los casi $6,00 \mathrm{~m}$. de luz de la bóveda ${ }^{16}$. Con esta bóveda se asocian también algunas de las series de los telamones de terracota encontrados en las termas. Contando con semejante dispositivo, el aspecto de la sala fregelana es comparable al del tepidarium de las termas del Foro de Pompeya, muy posterior, y permite constatar la poca originalidad del ambiente pompeyano. Debido a la pérdida de los alzados no es posible asegurar la existencia de nichos entre telamones, aunque esta eventualidad es plausible.

En otros casos de termas precoces como los de L'Almoina y Musarna, estancias análogas que, como la sala fregelana, se caracterizan por su posición respecto al caldarium y por la presencia en ellas de un banco fijo, han sido interpretados como tepidaria. En Cabrera del Mar la sala cuadrada identificada con el tepidarium no dispone de banco fijo. En torno a sus paredes corre un refuerzo murario que no puede ser confundido con un poyete, documentado también en el caldarium, pero no así en el apodyterium. Albert Martín sugiere, con razón, asociar a este elemento con las hornacinas que deberían abrirse en las paredes de estas estancias. Casos análogos de nichos en ambientes clasificados como tepidaria abundan en las termas tardorrepublicanas, con el caso del tepidarium de las termas del Foro de Pompeya como uno de los exponentes más llamativos. Con todo, la incertidumbre con respecto a la posible función de tepidarium de esta sala fregelana es consecuencia de la falta de otro 
ambiente susceptible de ser identificado como apodyterium. El sector occidental cuenta aparentemente con dos de las tres salas principales, típicas de los baños tripartitos del siglo II a.C. y una de ellas es un caldarium. Entre los espacios limítrofes, sólo el ámbito 12 podría haber desempeñado la función restante, si bien cualquier propuesta al respecto sería, en el estado actual de la documentación, mera especulación.

La cuestión de la localización de un tercer ambiente no es nada trivial, vista la antigüedad del edificio fregelano y su condición de exponente más antiguo entre los establecimientos de esta tipología conocidos hasta la fecha. De hecho, la diferenciación entre apodyterium y tepidarium en las termas romanas parece bastante precoz, vistos los casos, arriba mencionados de establecimientos que cuentan con sendos elementos, ya en el siglo II a.C. La introducción del frigidarium, en cambio, se suele considerar un evento más tardío. El número y la disposición de las estan-

17. Sobre la problemática, véanse, entre otros, ScHNEIDER 1924, 347; Hartmann 1920, 159 ss.; Delorme 1949, 407 s.; GinOUVÉs 1962, 136 s.; BRÖNDNER 1977; 1982; NielSen 1990, 11 ss.; 159 ss.; YeGÜl 1992, 384; Cfr. Cels. De Medicina 2, 17; Mart. 6,42; Srtab. III 3,6

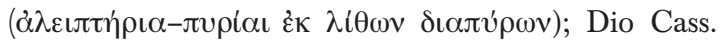

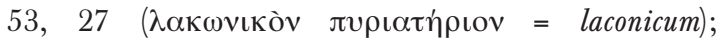

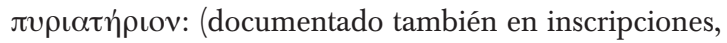
por ejemplo, IG IV, 454 A; V ${ }^{1} 938$; VII 1777) Eup. fr. 108 Edmonds; Arist. Probl. 2, 11; 29-32; Plut. Cim. 1,6. El pasaje de Plutarco y otros indicios tan inducido a algunos investigadores (GINOUVÉs 1962, 139; cfr. Foss 1975) a asimilar el $\pi v \rho \iota \alpha \tau \eta \dot{\eta}$ $(\alpha \lambda \varepsilon เ \pi \tau \eta \dot{\rho} \rho\llcorner\mathrm{v})$. La contraposición vitruviana de los términos laconicum y (concamerata) sudatio es un problema aún abierto (Vitr. V 11,2; cfr. V 10,5: laconicum sudationesque sunt coniungendae tepidario; algunos autores dudan que las sudationes correspondan a ambientes específicos). Con frecuencia, laconicum y (concamerata) sudatio se tratan en la bibliografía como sinónimos, lo mismo que sudatorium (Plaut. Stich. 226 ss.; Vitr. II 6; Sen. Ep. V 51,6), contribuyendo a la confusión. Especialmente grave es la casi constante confusión entre sudatio y sudatorium, absolutamente innecesaria ( $c f r$. las justificadas advertencias en NiELSEN 1990, 160). Algunos de los investigadores que reconocen en el laconicum-

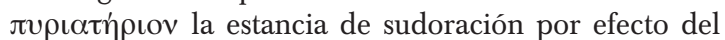
calor seco, suelen conferir a las sudationes el papel de estancias de sudoración por efecto de calor húmedo. Otros, sin embargo, siguiendo a Ginouvés, asocian la sudoración por efecto de calor húmedo o vapor con el

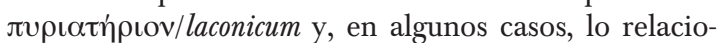
nan con las piedras incandescentes utilizadas en los $\pi v \rho \iota \alpha \tau \rho \iota \alpha$ "seguramente para hervir agua" (Almagro-Álvarez 1993, 198). Los defensores de esta última opción se ven confirmados también por hallazgos como el del laconicum de la casa helenística E2 de Monte Iato, que constituye un añadido de fase poste- cias en el sector occidental de las termas de Fregellae podría conducir hacia un esquema en el que la diferenciación entre apodyterium y tepidarium no se hubiese aún manifestado. En este supuesto, el mismo espacio podría haber desempeñado ambas funciones. Una respuesta definitiva podría derivar a partir del estudio de los ambientes de la I fase, cuya distribución y articulación en el espacio termal se anuncia muy prometedora con respecto a este tipo de cuestiones.

El pequeño ambiente 15 ocupa una posición con respecto al praefurnium, que lo convierte en un apéndice del mismo. De hecho, no se documenta ningún muro divisorio distinto del cierre frontal del horno, realizado en un opus testaceum típico de Fregellae, interpuesto entre sendos dispositivos. El ámbito se interpreta como una estufa, destinada al baño de sudor. En efecto, a juzgar por su posición junto al horno, sus pequeñas dimensiones y su sistema de calefacción subterránea (una especie de prolongación del horno,

rior: en el centro de esta estancia circular, apareció un recipiente de terracota encajado en el suelo, que se encontró lleno de piedras quemadas (ISLER 200; DE Algelis 2001, 190). Ante la dificultad de distinguir con claridad entre las funciones del laconicum, de la concamerata sudatio y del sudatorium muchos investigadores aplican a conveniencia uno u otro término a estancias calefactadas de pequeño tamaño, pese a la falta de datos explícitos sobre la modalidad de baño de sudor o de vapor practicados en ellas, aumentando así la confusión existente. El parámetro vitruviano de la forma circular de los laconica sirve a menudo de criterio excluyente a la hora de atribuir funciones de laconicum a una estancia de forma no circular. La concamerata sudatio vitruviana (que algunos identifican con el caldarium), en cambio, en cuyas esquinas opuestas se abren el laconicum y la calda lavatio respectivamente, ha de ser longitudine duplex quam latitudo, al menos en los baños de las palaestrae. Otra dificultad añadida concierne a la ya mencionada identificación, con frecuencia asumida como evidente, entre sudatio vitruviana y sudatorium, este último explícitamente relacionado por Séneca con baños de sudor a partir de calor seco. A este propósito cabe señalar, que, a falta de referencias a otro tipo de baño de sudor en el texto de Séneca, el parentesco terminológico entre sudatio y sudatorium no autoriza su identificación semántica stricto sensu. Con respecto a la problemática del nombre de laconicum, cabe señalar que las recientes excavaciones de las termas euriclideas (?) de Esparta (noticia en BlaCKAMAN 2001, 34, con bibliografía) no permiten intuir rasgos epicorios (lacónicas) en este establecimiento de finales del siglo I a.C., de traza típicamente romana. En todo caso, las identificaciones de los varios ambientes de este conjunto propuestas por sus excavadores invitan al escepticismo. Se desconocen las características del $\beta \alpha \lambda \alpha v \varepsilon i ̂ o v$ helenístico de Esparta, documentado para el año 180 a. C. (Pol. XXXIV 7, 6). 
similar al praefurnium de las termas Republicanas de Pompeya) y, muy probablemente, parietal, es plausible que la sudoración se lograba por efecto del calor seco (siccus calor, aridus vapor), resultado de las altas temperaturas alcanzadas en el interior del ambiente. El problema terminológico surge con fuerza ante una estancia de tales características morfológicas y cronológicas. La utilización del término laconicum ${ }^{17}$ podría resultar poco prudente, vistas las incertidumbres que aún rodean el término, las características específicas de estas instalaciones (en especial la planta circular) y la naturaleza de los baños de sudor efectuados en este tipo de estancias ${ }^{18}$. Es preferible servirnos de un término como sudatorium ${ }^{19}$, aparentemente más genérico, que quizás se adapta mejor a las características de la sala fregelana ${ }^{20}$, ya que hace referencia a la función desempeñada por el ambiente.

La sala 16 corresponde a un caldarium, del tipo ya estandarizado en el siglo II a.C., prácticamente idéntico a los ambientes análogos de Cabrera del Mar, L'Almoina y Musarna, aunque de dimensiones mayores. La reconstrucción de sus alzados no es posible más allá de algunos aspectos genéricos. Como ocurre con el ambiente 14, la decoración parietal con pinturas de I estilo parece asegurada, a juzgar por los restos de revestimiento hallados en su interior. Más difícil se presenta la reconstrucción de la cubierta, puesto que la anchura de la estancia $(7,40 \mathrm{~m}$.) es excesiva para suponer la existencia de una bóveda hecha con dovelas de opus figlinum.

Algunas peculiaridades, que diferencian este

18. El término, documentado en el Ágora de los itálicos de Delos (CIL I 2252), reaparece en relación con las reformas de las Termas Estabianas del período postsilano: CIL I 1251; X 829. Por otra parte, cabría quizás, reflexionar desde la perspectiva de M. Almagro Gorbea y J. R. Álvarez Sanchís (Almagro-Álvarez 1993) sobre las causas de la existencia de una sala de sudoración sólo en el sector masculino de las termas de Fregellae: quizás, no se trata sólo de una comodidad más, sino también de una reminiscencia de tradiciones antiguas, que asociaban el baño de sudor con la iniciación masculina y los grupos guerreros. Desde éste mismo ángulo se interpreta también el baño de tipo lacónico (iniciático y propio de guerreros), cuya memoria se supone que haya sobrevivido en el baño de sudor practicado en los laconica.

19. Cfr. CoARElli 1998, 61.

20. Sen. Ep. 51,6: quid cum sudatoriis, in que siccus vapor corpora exhausurus includitur? Cfr. Plaut. Stich. 226: unctiones Graecae sudatoriae. NiELSEN (Nielsen 1990, 159 s.) considera que este tipo de estancia "had both suspensura and tubulation and arose after the invention of espacio fregelano de sus homólogos de Cabrera del Mar, L'Almoina, Musarna y también de otros de fecha posterior, se ponen de manifiesto con respecto al alveus. Aquí, a diferencia de los casos citados, la bañera se desarrolla por debajo de la rasante del caldarium y, por lo que se ha podido comprobar, carece de calefacción subterránea ${ }^{21}$. Tal disposición implica que el desagüe no se efectuaba sobre el pavimento de la estancia. Otro dato de interés concierne a la compartimentación del alveus, efectuada en un segundo momento por medio de muretes perpendiculares. Esta característica, que, aún sin ser del todo idéntica ${ }^{22}$, remite a la antigua disposición individual de las pilas de inmersión, típica de los baños griegos y, en cierto modo, también a los compartimentos con pila individual de la fase más antigua de las Termas Estabianas, parece un retroceso con respecto a la cultura colectiva del baño de inmersión de la época.

Ya se ha aludido a las posibles funciones auxiliares (leñera, etc.) del ambiente 19, situado a las espaldas del caldarium. La zona de servicios se complementa con el ambiente $18^{23}$ y el horno 17 , este último con doble cámara circular. La colocación de las calderas encima del horno ${ }^{24}$ es, también en el caso de Fregellae, una suposición legítima, plausible y, prácticamente, obligatoria. De gran interés resulta la técnica constructiva del horno, realizado con grandes fragmentos de tegulae con las aletas laterales colocadas en modo de formar los paramentos. Esta técnica, que confiere al paramento el aspecto de un muro de ladrillo, es típica de Fregellae y siempre asociada con

the latter... The sudatorium replaced the laconicum". A la luz del hallazgo fregelano, dotado de ambos sistemas, esta última afirmación ha de ser revisada.

21. Un dato que, de confirmarse, podría resultar sorprendente, puesto que el alveus del caldarium de la I fase disponía ya de esta comodidad.

22. Cada uno de los cuatro compartimentos del alveus fregelano tiene capacidad para más de una persona.

23. Para evitar confusiones, prescindimos aquí de conferir el nombre de propnigeum a esta estancia de servicio, a pesar de que se ajusta a las características establecidas en DeGBOMOnd 1984, 31-59; cfr. REBUfFAT 1991, 10; 13; 20. De hecho parece difícil conciliar esta interpretación con el iter vitruviano (Vitr. V 11,2: ... frigidarium, ab eoque iter in propnigeum in versura porticus).

24. En ese sentido el horno es una hypocausis, según la terminología vitruviana.

25. CoARELli 2000. 
las fases más antiguas de la ciudad ${ }^{25}$, bastante anteriores al siglo II a.C. El calor producido por el horno podría incrementar en cierta medida la temperatura en las estancias 14 y 16, aunque sólo el ambiente 15 revela una verdadera conexión con la fuente de calor. De hecho, los gases generados en las cámaras de combustión circulaban entre las pilae del hypocaustum del ambiente $15 \mathrm{y}$ en la red de tubuli que, con toda probabilidad, revestía sus paredes ${ }^{26}$. Algunos endebles indicios apuntan hacia la existencia de un sistema de transmisión del calor del horno también hacia el interior del pedestal del labrum del caldarium.

Dificultades de interpretación presenta el espacio 13, que ocupa una superficie de casi 147 $\mathrm{m}^{2}$ en la esquina noreste de las termas y su relación con los espacios contiguos, en especial con el ambiente 12. Aquí se han documentado signos de una reforma, que terminó reutilizando partes de algunas columnas en la construcción del muro poligonal que cierra las termas hacia el norte. Otro plinto y un fuste caído de columna se encontraron colocados, sin funcionalidad aparente, contra el mismo muro. En cambio, se han conservado in situ, alineados con el muro oriental del ambiente 12, los plintos de dos columnas, que invitan a interpretar el espacio, bien como zona porticada, bien como estancia hipóstila. En el primer caso, preferible por varias razones, el espacio resultaría susceptible de ser interpretado como palestra ${ }^{27}$. En efecto, además de éste, el otro espacio susceptible de ser identificado con la palestra es el espacio 7 (158 $\mathrm{m}^{2}$ aproximadamente), si admitimos la existencia en él del peristilo, si bien las reducidas dimensiones de la estructura rectangular, la presencia de pavimentación en su alrededor, así como la posible interpretación de ésta como piscina, desaconsejan la caracterización del espacio como palestra.

Habitualmente se suele rebajar hasta el siglo I a.C. la aparición de las palestras, consideradas ajenas a la mentalidad y la cultura romana (Vitruvio), en las termas republicanas ${ }^{28}$. El caso de la palestra de las Termas Estabianas, si bien difícilmente puede servir de paralelo, vistas las diferencias morfológicas de este espacio pompeyano, constituye, en todo caso, un buen indicio

26. Sobre estas características del sistema de calefacción fregelano, véase infra.

27. Un ejemplo de espacio de dimensiones reducidas, interpretado como palestra, aunque sin argumentos concluyentes, se encuentra en la fase más antigua de las termas republicanas de Baetulo.

28. Sobre la problemática y el papel de la palestraen el desarrollo de las termas, NIELSEN 1990, passim. de la pervivencia de las viejas influencias helénicas en esta zona costera, que se confirman en la denominada palestra samnítica de esta misma ciudad y en los gimnasios de la vecina Neapolis, aún en uso en época augustea ${ }^{29}$. Fregellae, desde siempre abierta al Golfo de Gaeta gracias al río Liris y el portus de Minturnae, mantenía naturalmente contactos con la costa. Más tarde, la aventura fregelana en Oriente, abrió, como para todo el mundo romano contemporáneo, un nuevo y trascendental capítulo cultural, con la introducción masiva de modelos helenísticos en la vida urbana. Por tanto, no se puede excluir a priori la eventual existencia de una palestra en las termas de Fregellae, si bien el problema podría encaminarse hacia su solución definitiva tras el estudio del gran espacio situado al norte de las termas, entre el muro poligonal y el decumanus 2, que muestra características que parecen armonizarse con el aspecto de las palestras conocidas en otros establecimientos posteriores.

\section{Cronología}

La cronología de las termas de Fregellae, como el resto de la ciudad, cuenta, afortunadamente, con un terminus post quem (313 a.C.) y un terminus ante quem (125 a.C.) absolutamente inamovibles. La totalidad de los hechos arquitectónicos de la ciudad se sitúa, en consecuencia, en este lapso de 188 años del período crucial entre la finalización de las Guerras Samníticas y los Gracos.

Todos los datos arqueológicos e históricos disponibles hasta la fecha permiten una división de la efímera historia de la ciudad en tres períodos ${ }^{30}$. El primero comprende la etapa inicial y todo el siglo III a.C., hasta la conclusión de la Guerra Anibálica (313-200 a.C. aproximadamente). Al final de este período Fregellae emerge como ciudad hegemónica entre las ciudades latinas fieles a Roma. El segundo período comprende el período post-anibálico hasta mediados del siglo II a.C. y está marcado, entre otras situaciones histórico-políticas, por las experiencias victoriosas romano-itálicas en el Oriente helenístico, con todas sus consecuencias (200-150 a.C. aproximadamente). El reflejo arqueológico de esta realidad consiste en una fase constructiva cargada de

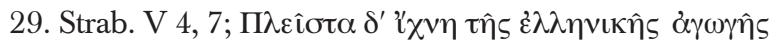

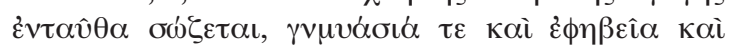

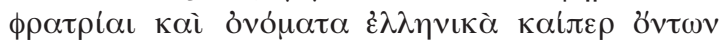

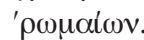

30. Periodización en CoARelli 1993; 1998, 29 s.

31. Sobre las características de estos movimientos CoARELli 1998, 34 ss. 
manifestaciones de prestigio, públicas y privadas. Durante las décadas finales de este período empieza a producirse un flujo migratorio de fregelanos hacia Roma, por un lado, y, en cambio, el asentamiento en Fregellae de varios miles de gentes procedentes del interior de la península, por otro ${ }^{31}$. El tercer período abarca las últimas décadas de vida de Fregellae (150-125 a.C.) y se caracteriza por un fenómeno de progresiva "samnitización" de la ciudad, con reflejos en la transformación del entorno urbano, y por los conflictos sociales y políticos, que desembocarán en la destrucción del 125 a.C. La claridad con la que esta secuencia se percibe en el registro arqueológico ha sido ilustrada en repetidas ocasiones por Filippo Coarelli.

También las termas fregelanas reflejan esta realidad. Los datos estratigráficos y tipológicos permiten situar cronológicamente la reconstrucción de la II fase a lo largo del segundo período (primera mitad del siglo II a.C.). Con respecto a la estratigrafía, cabe señalar que, por estos años, se documenta, tanto en las termas como en varias domus cercanas y en el mismo decumanus 1 , el abandono de las construcciones anteriores y el realce de la cota del suelo mediante grandes obras de relleno y nivelación, que, en algunos puntos supera los dos metros de potencia ${ }^{32}$. Las nuevas construcciones adquieren un carácter más monumental, si cabe, que las anteriores y algunas de ellas (sus tablina) se decoran ostentosamente con frisos de espléndidos relieves en terracota, verdaderos registros ideológicos, alusivos de las gestas de sus propietarios fregelanos en las guerras de Oriente ${ }^{33}$. La construcción de la II fase de las termas coincidió con un momento de gran actividad edificatoria, que además de la reconstrucción de los espacios y edificios públicos ciudadanos (foro, curia, comitium), se caracterizó por la construcción de una obra pública tan importante para las termas como el acueducto. Algunos indicios ${ }^{34}$ invitan a precisar mejor la cronología de la II fase de las termas, situándola en algún momento poco posterior de mediados

32. Sobre la datación, ibid., en especial 56 ss.; véase también CoARelli 1993.

33. Coarelli 1993

34. Cfr. CoARelli 1993; KaEnel 2000, en especial 153.

35. Sicilia, Magna Grecia y Marsella.

37. CoArelli; 1998, 62 ss.; 2000, 93 ss.

38. Esta policromía recuerda a algunos pavimentos de tumbas macedonias con decoración a rombos, del siglo III a. C., si bien obtenidas con materiales diferentes (así, en la tumba 3 de Kastas). La losetas con forma de escamas, de distintas tonalidades, que logran una rebuscada policromía desaparece de los pavimentos fregelanos recen- de la década de los ochenta del siglo II a.C.

La cronología de la I fase de las termas está todavía en estudio, puesto que su excavación acaba de finalizar. En todo caso, su datación a lo largo del siglo III a.C. está fuera de dudas. En principio, algunos datos internos y otros externos al edificio sugieren una notable antigüedad, acercando este primer establecimiento termal a las fechas de construcción de los $\beta \alpha \lambda \alpha v \varepsilon \hat{\imath} \alpha$ sicilianos y al período II de las Termas Estabianas. Por estas fechas no se conocen en occidente otros establecimientos de baños públicos fuera del contexto griego o afines ${ }^{35}$, ni siquiera en Campania ${ }^{36}$ (lo que no significa que no los hubo). La construcción fregelana se llevó a cabo en un solar situado en el corazón de un sector residencial próximo al foro, en el que se documentan domus (caso de la domus 7, frente a las termas) fechables aún en la primera etapa de la colonia refundada ${ }^{37}$. Las tipologías de los pavimentos de opus signimum, en especial la composición del mortero y la tipología de las teselas, son comparables a los documentados en algunas domus datables, a partir de la cerámica, a comienzos del siglo III a.C. El tipo de pavimento de opus figlinum con losetas en forma de escama o pelta polícromas no vuelve a aparecer en otras construcciones fregelanas ${ }^{38}$, lo mismo que aquel de fragmentos de tejas polícromas, colocadas de canto. En cambio, el tipo de la loseta romboidal de módulo grande, que bordea el alveus, sólo reaparece en el impluvium de la domus 7, cuya antigüedad acabamos de subrayar. Sólo los tipos de losetas en forma de escamas y rombo (módulo pequeño) de color rojo vivo, perdurarán también en las etapas posteriores. La cerámica también parece apoyar una fecha alta, no posterior a mediados del siglo III a.C.

\section{Paralelos}

La mayoría de las características del edificio de la II fase de las termas de Fregellae, lo mismo que algunas de la I fase, encuentran paralelos en establecimientos republicanos de Italia, Galia e Hispania,

tiores. Variantes (bicromía) se documentan en otros contextos mucho más tarde (por ejemplo, en las termas de L'Almoina, de finales del siglo II a. C.).

39. Entre otros ejemplos: Villa Prato (BROISE-LAFON 1980, 111 s.; LAFON 1991); villa de Ciampino (BROISE 1994); villa de Grottarossa (Saxa rubra: Stefani 1945; cfr. FABbricotti 1976, 82; CAPUTO 1991, 223 ss.); Vulci, Casa del Cripropórtico (BROISE-JOVILET 1991, 85 ss.).

40. De Cazanove-Jovilet 1984; Barbieri-Broise-Jovilet 1985; Broise Jovilet 1991. Un segundo baño mucho más simple se documenta en el macellum de Musarna (BROISE-JOVILET 1993; 1994). 
si bien se trata siempre de conjuntos posteriores. En Italia, además de algunos baños privados de la segunda mitad del siglo II a.C. o posteriores, en los que se aprecian criterios organizativos y soluciones técnicas comparables a los de Fregellae ${ }^{39}$, destaca el conjunto de carácter público de Musarna, que ofrece el paralelo más sobresaliente ${ }^{40}$, encuadrado aún dentro de los límites cronológicos del siglo II a.C. El baño de Via Sistina, en Roma, más tardío, también ofrece analogías a pesar de la forma de su caldarium y la dificultad de una lectura segura del resto de sus ambientes ${ }^{41}$. En ámbito campano, además del caso de las Termas Estabianas, una amplia serie de termas del siglo I a.C., bien conocidas gracias a los ejemplos de Pompeya y Herculano, constituyen el punto de llegada de la cultura y arquitectura balnear a partir de experiencias de los dos siglos anteriores, como las documentadas en Fregellae. Especial atención merece la difusión del modelo documentado en el edificio de la II fase de Fregellae, en las costas mediterráneas de España y Francia, que, en algún caso, es incluso anterior a mediados del siglo II a.C. Se trata de modelos directamente importados desde las zonas de procedencia de los colonos o emigrantes itálicos y realizados seguramente por técnicos oriundos de las mismas zonas. Algunos de los más antiguos representantes de estos establecimientos (sobre todo los de Cabrera del $\mathrm{Mar}^{42}$ y de Valencia ${ }^{43}$ ) ponen de manifiesto la gran difusión del fenómeno de los baños públicos entre los romanos e itálicos a lo largo del siglo II a.C., hecho que presupone un buen arraigo de la cultura balnear ya desde fechas anteriores, tal y como anuncian, además de las fuentes, las primeras fases de las Termas Estabianas y, ahora, las dos fases de las termas de Fregellae. En España, los casos de Ampurias (éste, quizás, aún

41. FioRini 1988 (mediados del siglo I a. C.); cfr. CAPUTO 1991, 265 ss. (sugiere realzar generosamente la fecha propuesta por Fiorini); BROISE 1994, 28-29.

42. MARTÍN 2000.

43. Ribera 1993; 1998; MARTín-Ribera 199; 2000.

44. Una síntesis en Nolla 2000, con referencias bibliográficas.

45. Bouet 200, 36, con bibliografía anterior.

46. Morena-Counord 1994, 58 s.; Bouet 2000, 36.

47. Para estas cuestiones remitimos, de momento, a algunos de los principales trabajos en los que se exponen las distintas visiones, algunas de ellas superadas hace tiempo: Sgobbo 1928; di Capua 1929; Crova 1956; EsCHEbaCh 1973; 1979; FAbBRicotTi 1976; NielSEN 1985; 1990; Delaine 1988; 1989; 1993; cfr. Delorme 1960; GiNOUVÈS 1962; LAFON 1991; BROISE-JOVILET 1991; BROISE 1994; FAGAN 2001.

48. NieLSEN 1985, 85 ss.; 1990, $26 \mathrm{~s}$.

49. El uso de opus figlinum en los pavimentos de ambos establecimientos es un dato poco relevante a efectos de comparación tipológica de los dos baños. del siglo II a.C.), Baetulo, Azaila y Arcóbriga confirman la fortuna del modelo aún durante la primeras décadas del siglo I a.C. ${ }^{44}$ Entre finales del siglo II a.C. y comienzos del siguiente, se documentan edificios de este tipo también en Francia, caso éste del establecimiento de Lascours (Ceilheset-Rocozels, Hérault) ${ }^{45}$ y, sobre todo, del edificio de la Rue Aubernon, en Antibes (Alpes-Maritimes) ${ }^{46}$, con caldarium muy próximo al de Musarna.

No es el caso de retomar aquí la problemática sobre la dialéctica entre los $\beta \alpha \lambda \alpha v \varepsilon i \hat{\alpha}$ helenísticos de Sicilia, Magna Grecia y de algunas ciudades campanas no griegas, por un lado, y los establecimientos públicos o privados que se documentan, a lo largo del siglo II a.C. (aunque seguramente de tradición anterior), en áreas de la Campania y de Italia central, por otro. Tampoco permiten los límites de éste artículo una exposición de la problemática sobre la supuesta evolución de estos últimos a partir de algún tipo de baño itálico primitivo, colectivo o privado ${ }^{47}$. Sin embargo, es oportuno recordar, que el modelo de las Termas Estabianas de las fases II-III de Eschebach (siglos IV-III a.C.), un verdadero $\beta \alpha \lambda \alpha v \varepsilon \hat{\imath} o v$ con sus celdas de bañeras de inmersión individuales, su loutron $\mathrm{y}$, posiblemente, con el añadido de una estancia (el futuro apodyterium femenino) dotada de bañeras para baños de aspersión, $\pi u ́ \varepsilon \lambda o u$, según el modelo de los $\beta \alpha \lambda \alpha v \varepsilon \hat{\imath} \alpha^{48}$, no parece reflejado en la I fase de los baños de Fregellae $^{49}$. En cambio, muchos de los elementos de la remodelación de las Termas Estabianas del período IV de Eschebach (siglo II a.C.) se perciben fácilmente en las termas de Fregellae de la II fase, mientras que varios de estos elementos aparecen bien definidos ya en la I fase

50. Un labrum relleno de tierra compactada y recubierta cuidadosamente con fragmentos de tejas (conservadas en parte y con restos de combustión) formando una especie de omphalos, se ha encontrado apoyado directamente sobre el pavimento. Esta artilugio, probablemente in situ, podría haber desempeñado el papel de fuente de calor, quizás como una especie de brasero (ilabrum cum focolo?: CIL IX 3677, Marsi Marruvium. Una sugerencia interpretativa distinta de este oscuro elemento en Nielsen 1990, 33). Sobre los ỏ $\phi \alpha \lambda$ oí en los baños griegos GinOUVÈs 1962, 198 (con fuentes). Nielsen (NIELSEN 1990, 7; 9) reconoce los ó $\phi \alpha \lambda$ oí en los hoyos de los $\pi v \varepsilon \lambda$ oí de las rotondas, sin embargo, cfr. Crat. fr. 50 (objetos de bronce en el centro de las rotondas); también Ath. XI 501 c-

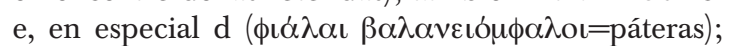
Licofrón, al que alude Ateneo, usa la expresión

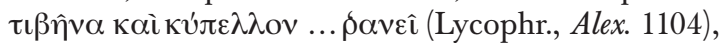

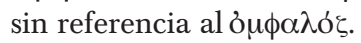


de las mismas. En efecto, la organización espacial del edificio fregelano de la I fase indica la existencia de varios ambientes bien articulados, cada uno de ellos aparentemente con características específicas: bien reconocible es el caldarium, dotado de alveus calefactado; al sur del caldarium, otro ambiente desempeña, quizás, el papel de tepidarium $^{50}$. En el edificio de I fase existen además varios elementos individuales típicos de baños posteriores, entre los que cabe destacar la presencia de, al menos, una estancia abovedada con decoración parietal con filas de telamones, un alveus colectivo, un labrum y un sistema de calefacción ${ }^{51}$ con conducto análogo a los dispositivos de algunos $\beta \alpha \lambda \alpha v \varepsilon \hat{\imath} \alpha$ greco-occidentales contemporáneos y de baños romanos posteriores (Musarna, Cabrera del Mar, Valentia, Ampurias, Baetulo etc.). Estos datos demuestran, que en las termas de Fregellae se contaba, ya desde el siglo III a.C., con muchos, si no con todos, los elementos típicos de baños posteriores, incluidas las Termas Estabianas de la fase IV de Eschebach, siempre que sus estimaciones cronológicas sean ciertas. En cambio, como ya se ha dicho, no aparecen en Fregellae elementos comparables con las fases anteriores de las Termas Estabianas, hecho que confirma la pervivencia de modelos arcaicos en el edificio pompeyano (en especial las pequeñas bañeras en celdas individuales y, en su caso, los $\pi u ́ \varepsilon \lambda o \imath)$ hasta su remodelación del siglo II a.C. (período IV).

En ese sentido, resulta difícil mantener como guía para la evolución de los baños en suelo itálico las etapas individualizadas en la Termas Estabianas según la periodización de Eschebach. El modelo que predominará durante el siglo II a.C. se anuncia ya en la I fase de las termas de Fregellae, del siglo III a.C., con formas arquitectónicas y soluciones técnicas y tecnológicas muy

51. Sobre estos elementos, infra.

52. Delaine 2000: Broise 1994; Gela (OrlandiniADAMESTEANU 1960; GinOUVÉs 1962, 429 ss.; finales siglo IV. a.C., con reformas poco antes del año 282 a.C.), Morgantina (AlLEN 1974; comienzos siglo III a.C.), Siracusa (Cultera 1938; GinOuvÉs 1962, 162; primera mitad del siglo III) y, en especial, Megara Hiblea (VIllard-Auberson 1982, 49 ss.; primera mitad del siglo III a.C.). En una casa helenística de Monte Iato, el baño privado de principios del siglo II a.C. está dotado de alveus de inmersión calefactado por un gran conducto subterráneo (ISLER 2000). Baterías de bañeras individuales, calefactadas con un sistema análogo ya en Gortys de Arcadia (GINOUVÈs 1959). Fuera de Sicilia destaca el $\beta \alpha \lambda \alpha v \varepsilon \hat{\imath}$ ov de Velia (comienzos del siglo III a.C.; JoHANNOWSKI 1982). En ámbito campano, el establecimiento de Cuma bien desarrolladas, aún ausentes en las Termas Estabianas. En el estado actual de nuestros conocimientos sobre los edificios campanos del siglo III a.C., la realidad de la I fase de Fregellae apunta directamente hacia otros contextos. En efecto, durante la primera mitad del siglo III a.C. (si no antes) y en la medida que sus restos permiten intuir, en los establecimientos de Sicilia y Magna Grecia se anuncian algunos de los rasgos típicos de los balnea/ae romano-itálicos posteriores, tanto en establecimientos públicos ${ }^{52}$ como privados ${ }^{53}$. Estos rasgos, si bien sólidamente enmarcados en el concepto de $\beta \alpha \lambda \alpha v \varepsilon i ̂ o v$ son tanto de índole arquitectónica como, sobre todo, funcional. Así, por ejemplo, el edificio de Megara Hiblea ${ }^{54}$ presenta en la disposición y características técnicas de algunos ambientes, rasgos comparables con los del establecimiento fregelano de I fase. Esto no quiere decir que el ámbito siciliano fuese el interlocutor directo de Fregellae, máxime cuando el conocimiento actual de las áreas intermedias, en especial Campania, no permite rastrear con seguridad los pasos seguidos. No obstante, la influencia siciliana, directa o, más probablemente, indirecta, se percibe igualmente en otros elementos fregelanos, como las figuras de los telamones ${ }^{55}$. Estas observaciones, unidas a la alta capacidad técnica de los arquitectos fregelanos (piénsese en las estancias abovedadas) y, sobre todo, el contexto histórico en el que estos hechos arquitectónicos se manifiestan, invitan a mirar también, y sobre todo, en otra dirección, a menudo infravalorada en el debate sobre la difusión de los modelos de las estructuras balneares: Roma.

Las principales características funcionales de los baños sicilianos (y magnogrecos) que no parecen reproducirse en el edificio de Fregellae más precoz, como tampoco en el de segunda fase (al igual que ocurre con otros baños del siglo II a.C.)

(ante 180 a.C.; Gallina 1970; Tocco 1976; NiELSEN 1990, 29) se acerca al modelo de la fase IV de las Termas Estabianas. Similar situación también en Marsella (Bouet 2000).

53. Sobre la evolución del baño romano a partir de modelos sicilianos y magnogrecos, pero no orientales, Delaine 1989.

54. Según lectura propuesta por Broise (BROISE 1994, 17 ss.)

55. Quizás, también el empleo del opus figlinum (losetas) en los pavimentos fregelanos sea un indicio de implantación de modas sicilianas. Para el siglo III a.C. pavimentos de este tipo se documentan tanto en la Sicilia griega y púnica, como en el norte de África, en especial en la zona de Cap Bon (Kerkouane).

56. También la organización del itinerario puede resultar diferente. 
son, fundamentalmente, el recorrido "centrífugo", la presencia de la tradicional tholos con las pequeñas bañeras para el baño de aspersión (hip baths) $y$, en algunos casos, la posible presencia de bañeras de inmersión individuales en lugar de los alvei colectivos, caso éste del $\beta \alpha \lambda \alpha v \varepsilon i ̂ o v$ de Gela ${ }^{56}$. Otra serie de posibles funciones, perceptibles en el número relativamente alto de las estancias de estos baños (hecho que parece presuponer una mayor diversificación de servicios en algunos de ellos, como en Megara Hiblea), no se puede tomar en consideración con la misma certeza, por falta de datos más explícitos. En todo caso, las primeras impresiones que ofrece la excavación par-

57. Para Sicilia, BROISE 1994.

58. Al igual que otro exponente occidental, los baños de la rue Leca, en Marsella, descubiertos recientemente: Conche 1999; Hermary-Hesnard-Treziny 1999, 76 s.; Hesnard-Moliner-Conche-Bouiron 1999, 93 ss.; BouEt 2000, 35 s. (de éste último proceden las referencias bibliográficas aquí citadas).

59. Contra Delaine 1989, 119 ss.

60. GinouvÈs 1959; 1962; Pouilloux 1960.

61. Chrisostomou 1996, 111 ss. Los baños $(9,00 \times 6,00$ $\mathrm{m}$. aproximadamente), situados al norte del gran peristilo, que caracteriza al denominado edificio $\mathrm{V}$, son aparentemente destinados al personal auxiliar del palacio. Constan de tres salas rectangulares y de una estancia alargada de servicio (IV, 5,70 x 2,15 m.), dotada de horno que atraviesa el muro divisorio de la sala más septentrional, desarrollándose parcialmente en el interior de ésta. Esta última sala (III, 3,05 x 3,10 m.) ha sido interpretada, quizás precipitadamente, como

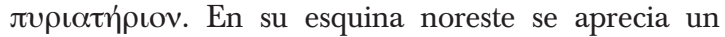
soporte triangular en fábrica de ladrillo, interpretada como base de algún muebe de madera para la custodia de utensilios. El horno (descrito como semicircular y designado con el término neogriego $\varepsilon \sigma \tau i \alpha$ ) invade ligeramente el espacio de esta habitación. Tres toscos sillares-pilastras de arenisca enclavadas en el interior del horno, han sido interpretados como soporte de la caldera. La sala intermedia (II 2,15 x 2,70 m.) cuenta con un banco fijo exento. La sala más meridional (I, $4,40 \times 3,00 \mathrm{~m}$.) presenta, encastrada en el suelo, una bañera lítica $(1,95 \times 0,85 \times 0,55 \mathrm{~m}$.) con revestimiento hidráulico en su interior y en su borde. Las estancias de baño están pavimentadas con una lechada de revestimiento hidráulico, extendida sobre un suelo de fragmentos de tejas colocadas verticalmente. El acceso al complejo se sitúa en la vertiente meridional, siendo la secuencia lógica del itinerario de sur hacia norte y retroceso (salas I-II-III; axial row type). Pese a sus reducidas dimensiones, su carácter privado y sus diferencias con los baños itálicos del siglo II a.C., el conjunto, dotado de fuente de calor propia y ambiente de servicio (leñera, etc.), evoca una articulación tipo apodyterium/frigidarium-tepidarium-caldarium. La ausencia de bañera en la sala III, podría sencillamente ser debida al carácter móvil de la misma. El banco lítico de la estancia II, destinado, al parecer, a más de una cial de la I fase de las termas fregelanas parecen confirmar una multiplicidad articulada de servicios también en nuestro caso. Una multiplicidad, que tiende a reducirse durante la II fase, si bien varios ambientes, especialmente los de la zona frontal, quedan sin poder ser interpretados.

Sin embargo, aún teniendo en cuenta ciertas particularidades de la arquitectura y cultura balnear siciliana y magnogreca, tales como su articulación según un plan centrífugo de recorrido ${ }^{57}$, parece difícil disociar estos establecimientos ${ }^{58} \mathrm{de}$ las experiencias puestas en marcha en otros complejos del mundo griego ${ }^{59}$, como, por ejemplo, en

persona, invita a pensar que, sin bien el conjunto se inscribe en la esfera de lo privado (en la medida que se puede considerar privado un complejo palacial de las características del de Pela) es de uso colectivo. La cronología de estos baños se remonta a las primeras décadas del siglo III a.C. (período de Antígono Gonatas).

62. Sobre los Grandes Baños del mismo conjunto palacial, asociados a una palestra, CHRisostomou 1996, 114 ss.; 1998; Misailidou Despotidou 1998. La relación entre espacios de entrenamiento físico (gimnasios) y prácticas de baños calientes en la Macedonia helenística se documentan en las fuentes epigráficas y, posiblemente, literarias (documentos y debate en GAUTHIER-HATzOPOULOS 1993).

63. ThÉmelis 1999,90 s. Se trata de un edificio rectangular $(34,50 \times 23,00$ m.) ubicado inmediatamente al sur del Asklepieion y construido principalmente con sillares de piedra caliza. Está caracterizado por un amplio espacio cuadrado (quizás con peristilo) dotado de una gran "piscina" en su centro, que ocupa la esquina noroeste del conjunto. El edificio está jalonado por un largo y amplio corredor en su flanco norte y otro, más estrecho, en su flanco sur. Las estancias de baño y sus anexos (al menos 8; ninguna de ellas es circular) ocupan las dos terceras partes meridionales del edificio. Destaca el gran horno, con cámara circular y largo canal de alimentación (con reformas de época augustea), ubicado entre la batería de las principales estancias y el corredor septentrional. El estado de conservación del edificio no permite la lectura funcional de cada sala. No obstante, parece probable que la más grande de ellas (ambiente 14), que es la que más se beneficia del calor por su disposición con respecto al horno, tuviese relación con baños de agua caliente. Algunas huellas rectangulares, documentadas en las lastras de piedra del solado de la estancia, han sido interpretados como encajes para el asiento de bañeras. El conjunto no guarda relación con espacios de ejercicio. Su cronología, tardoclásica o, más probablemente, helenística, no está fijada con seguridad, aunque su inmediato entorno, con fases del siglo IV a.C., es objeto, hacia finales del siglo III a.C. y comienzos del siguiente, de una reconstrucción total imponente y especialmente monumental, sólo comparable con los programas edilicios de los reinos helenísticos, en especial, de Pérgamo. 
el bien conocido $\beta \alpha \lambda \alpha v \varepsilon i ̂ o v$ de Gortys, en Arcadia (finales siglo IV a.C.) ${ }^{60}$. Quizás, no es una casualidad, que en el conjunto fregelano se perciban, en mayor o menor medida, ciertos esquemas que caracterizan precisamente a algunos conjuntos, como, por ejemplo, los denominados Pequeños Baños ${ }^{61}$ del palacio real de Pela (principios siglo III a.C.) ${ }^{62}$ o el $\beta \alpha \lambda \alpha v \varepsilon \hat{\imath}$ ov de Mesene ${ }^{63}$ (edificio E; siglos IV-II a.C.), por citar dos casos que responden a necesidades diferentes.

La I fase de las termas de Fregellae viene a confirmar la existencia de una sólida cultura balnear en el Lacio al menos desde el siglo III a.C., abierta a los estimulos llegados desde contextos geográficos y culturales del sur de Italia (campano, magnogreco y siciliano) y, probablemente, no ajena a las experiencias del Oriente helénico. Este dato invita a reflexionar también sobre el papel de Roma con respecto a la configuración y difusión de este tipo de manifestaciones culturales y arquitectónicas, probablemente vinculadas al progresivo auge del sistema de abastecimiento hídrico de la Urbs a partir de finales del siglo IV a.C. El establecimiento de Vía Sistina, aunque tardío, constituye, en todo caso, un indicio de la antigüedad de este tipo de establecimientos en la capital, confirmando, en cierta medida, las alusiones de las fuentes literarias, incluso cuando éstas, como la célebre afirmación de Catón, se interpretan a menudo como pruebas de lo contrario.

\section{Aspectos téCnicos y CUlturales}

De los numerosos y novedosos datos que aportan las dos fases del edificio fregelano, ambas de cronología anterior a los establecimientos de este tipo (denominados, a veces, romano-itálicos) conocidos hasta la fecha, cabe

64. GiNOUVÈS 1962, 197 s.; NIELSEN 1990, 147; YEGÜL 1992, $32 \mathrm{~s}$.

65. Varr. $L L$ IX 68.

66. En la época de Varrón se empleaban los términos balneum y balnea. El término balineae aparece ya en Plauto.

67. FIORINI 1988.

68. CAPUTO 1991, que propone realzar la cronología propuesta por Fiorini, se basa en la comparación del mosaico de la estancia principal del establecimiento romano, decorado con un motivo de recinto amurallado, con el motivo análogo documentado en la domus 7 de Fregellae (fase II).

69. La falta de registro arqueológico no esconde necesariamente una obstinada cultural de Roma hacia el pujante fenómeno social del baño en los términos que algunos investigadores han querido entrever en la célebre afirmación de Catón (Cat. Ap. Non. 155, 24): reseñar brevemente algunos, que marcan hitos importantes en el estudio de la cultura balnear romana. De hecho, las termas de Fregellae no sólo representan el ejemplo más antiguo de este modelo de termas urbanas del que tenemos constancia arqueológica, sino que permiten constatar la introducción temprana en el Lacio de elementos culturales y técnicos sólo comparables a los que se dan en el mundo griego contemporáneo del Sur de Italia, Sicilia y Grecia continental.

a) División en sectores

La primera característica de las termas de Fregellae concierne a su inserción, ya desde la I fase, en el tejido urbano, en el corazón de un sector residencial. Desde su primera fundación, el edificio aparece como una unidad arquitectónica bien definida, monumental y tipológicamente consolidada, poniendo de manifiesto el largo camino que ya había recorrido la cultura del baño colectivo en el área lacial en fechas aún tempranas. Además, su carácter público muestra la aceptación que ya gozaba dicha cultura en la sociedad itálica.

De las demás características del edificio destaca, al menos por lo que concierne a su II fase, la división en dos sectores, masculino y femenino, que anticipa varias décadas el considerado hasta ahora como primer caso conocido a través de la arqueología, el de las Termas Estabianas, confirmando plenamente las alusiones de las fuentes. Como es bien sabido, la bipartición de los establecimientos termales, que tiene larga tradición en el mundo griego ${ }^{64}$, se asocia por Varrón con los antiguos baños públicos de Roma ${ }^{65}$. Es precisamente esta duplicidad de servicios que induce a ese autor a justificar lo correcto de la voz balneae, que según él aplicaban los romanos de generaciones anteriores ${ }^{66}$ a los baños públicos de dobles

mihi puero... balneum non quotidianum (Catón nació en el 234 a.C.); la afirmación de Catón registra simplemente la situación que precede al contacto de Roma con Oriente y la consecuente introducción masiva de costumbres y luxuria helenísticas, pero en ningún caso excluye la existencia de establecimientos públicos en Roma antes de esta fecha. Al contrario, parece precisamente confirmar una más o menos moderada, para sus gustos, tradición balnear. El contacto de Roma con la Campania y con el mundo griego de la península italiana y de Sicilia, con todas sus implicaciones en el campo cultural, es un fenómeno que se remonta todavía a época arcaica, intensificándose tras la progresiva expansión romana hacia el sur a partir del siglo IV a.C. Sobre esta cuestión, una breve síntesis en NiELSEN 1990, 28 ss.

70. Gell. NA X 3,3. 
servicios. El texto varroniano no permite reconstruir la cronología de los primeros baños públicos de Roma. El ya mencionado establecimiento de Vía Sistina ${ }^{67}$ sólo data, en el mejor de los casos, de la segunda mitad del siglo II a.C. ${ }^{68}$ y no parece disponer de dobles servicios ${ }^{69}$. En cambio, estos se documentan en las fuentes en el caso de los baños de Teanum Sidicinum, para el año 123 a.C. ${ }^{70}$. El caso de Fregellae, donde la comparación entre el sector masculino y el femenino pone de manifiesto la superior calidad de los servicios del primero, permite ahora conocer un caso de balne$a e^{71}$ de estas características de principios del siglo II a.C. No se ha esclarecido aún si esta división existía ya en la I fase del edificio.

b) Sistemas de calefacción

Una de las aportaciones más espectaculares de las termas de Fregellae es el descubrimiento en el ambiente 12 del sofisticado sistema de calefacción subterránea y parietal, tipológicamente

71. Vista la noticia de Varrón, así como su uso por Plauto, prácticamente contemporáneo del edificio fregeliano, este término es el que mejor se ajusta a las características de las termas de Fregellae. Sin embargo, su aceptación aquí no excluye la posibilidad de que existiese también una palestra en el complejo, tal y como dejan intuir algunos datos. La división de Nielsen (NiELSEN 1990, 3) entre balnea/ae y thermae a partir de la presencia o no de palestra, pese a su utilidad, no responde necesariamente a la realidad terminológica del mundo antiguo, especialmente de fechas tan tempranas. De hecho, la palabra thermae, bien sea un neologismo latino a partir de un préstamo lingüístico, bien un término griego latinizado, sólo alude al calor que caracteriza estos establecimientos. Se nos escapa la razón que condujo a la utilización del término laco-

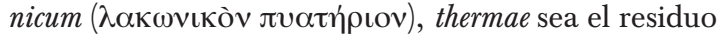
adjetival de una denominación en griego, formada en origen por el adjetivo y un nombre y aplicada, bien en una parte o en la totalidad del edificio de baños, bien en alguna de las principales prácticas que en él se efectuaban.

72. Utilizo aquí el término hypocaustum entendiendo, como muchos autores, el típico sistema area-pilae-pavimento, situado bajo las estancias y comunicado con una fuente de calor. No obstante, esta concesión no implica que asumimos como correcta esta terminología para este tipo de dispositivos, que Vitruvio parece denominar suspensura(e). Cabe recordar, que Plinio, el pri-

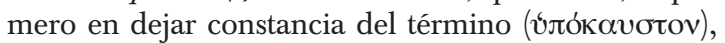
lo utiliza como adjetivo, aplicado bien a un unctorium, bien a un cubiculum: éste es, precisamente un correcto

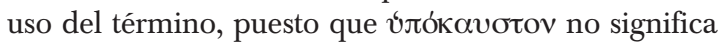
"lo que quema por debajo" (como entienden algunos), si no "lo que se quema (se calienta) por debajo" (por ejemplo, una estancia dotada de sistema de suspensurae o su pavimento). En este sentido, el término hypocaustum idéntico a los hypocausta ${ }^{72}$ posteriores compuestos por area-pilae-pavimento "suspendido". Se trata del primer ejemplo de hypocaustum de ese tipo conocido hasta la fecha en la arquitectura balnear grecorromana, aplicado a una estancia entera, aunque pequeña ${ }^{73}$. Este hecho permite dar definitivamente por zanjada la cuestión sobre la invención del hipocausto "canónico" por Sergius Orata $^{74}$ entre 95 y 90 a.C., tradicionalmente aceptada por la investigación, aunque puesta en duda recientemente, con argumentos diferentes, por Garrett Fagan ${ }^{75}$. El hallazgo de Fregellae demuestra que Orata pudo haber inventado cualquier sistema o dispositivo para sus cultivos de ostras, adaptado (o no) a los balnea por él mismo o por otros, pero es absolutamente seguro que no ha inventado el hypocaustum de pilae. Naturalmente, tampoco fue el inventor del sistema de calefacción de los alvei de los baños mediante canales alargados situados por debajo y conectados con el horno, como sabemos por los dispositivos aná-

podría no referirse a algún dispositivo de calefacción o estancia en especial, sino que, con valor adjetival, se aplica a cualquier ambiente calefactado por debajo, sea cual sea su sistema de calefacción (suspensura, canales, etc.). Al parecer, el término jamás ha perdido del todo su significado original, incluso cuando se usa como substantivo. En todo caso, no aplicaremos aquí este término a otros sistemas subterráneos de calefacción no provistos de pilae, a pesar de que muchos autores así lo hacen. El objetivo es evitar la confusión terminológica, que reina en los estudios de los edificios termales porque el uso del término se hace a conveniencia, tanto para referirse a la función del dispositivo, como a su tipología técnica-arquitectónica.

73. No es el caso de entrar aquí en el farragoso debate sobre la terminología a aplicar en los distintos sistemas de calefacción que se suelen encontrar en los subsuelos de los $\beta \alpha \lambda \alpha v \varepsilon \hat{\imath} \alpha$, de los balnea y de las termas en general. Es evidente, y no merece más comentarios, que cualquier sistema de calefacción subterránea conectada a una fuente de calor puede ser denominada, aunque erróneamente, hypocaustum. Sin embargo, la cuestión principal con respecto al hypocaustum no es cuándo y cómo aparecieron los sistemas de calefacción subterráneos, si no cuándo y cómo apareció lo que Vitruvio denomina suspensu$r a(e)$, es decir, lo que nosotros denominamos frecuentemente hypocaustum "normal", "canónico", "desarrollado", "verdadero", etc., compuesto por area, pilae y forjado (=suspensio) bajo el pavimento.

74. Cic. Hortens. Frr. 69B; K ap. Non. 194, 13; Plin. NHIX 168 (cfr. XXVI 16); Val. Max. IX 1,1; Macrob. Sat. III 15, 1-3. También debe replantearse el debate en torno a los baños de Olimpia (KunZE-SCHLEIf 1944).

75. FAGAN 1996.

76. Véase infra. 
logos de baños de Grecia, Magna Grecia, Sicilia, Italia central (entre ellos el caldarium de I fase de Fregellae $^{76}$ ) y España, de los siglos IV-II a.C.

De hecho, el dispositivo bajo el ámbito 12 de las termas de Fregellae es un verdadero hypocaustum, completamente desarrollado, que ocupa todo el subsuelo de la estancia. El forjado de tejas sobre las que se extendía el solado del ambiente (a menudo denominado suspensura en los estudios actuales), no se ha conservado in situ, aunque varios fragmentos de tejas bipedales, con una de las caras recubierta de una gruesa capa de opus signinum, fueron encontrados en los alrededores. En cambio, se conservan in situ $5 \times 4$ filas de pilae, algunas en buen estado, que descansan sobre un area de opus figlinum (baldosas de barro). Como ya se ha dicho con anterioridad, las pilae están realizadas con gruesas tejas planas o baldosas, recortadas ${ }^{77}$ en forma cuadrada, conformando elementos similares a los laterculi besales vitruvianos ${ }^{78} \mathrm{y}$ cogidas con argamasa, al parecer de tipo especial. Algunas de ellas presentan hasta siete elementos superpuestos, conservándose hasta una altura aproximada total de 0,35 m., aunque en origen eran más altas.

Fregellae ofrece, por tanto, la prueba definitiva sobre la efectiva utilización de ese sistema para calentar ambientes enteros ya desde las primeras décadas del siglo II a.C. El inamovible terminus ante quem del 125 a.C. hace del hypocaustum de Fregellae un antecesor absolutamente seguro del invento atribuido a Sergio Orata (principios del siglo I a.C.), demostrando claramente y sin necesidad de más comentarios, que Orata no fue el inventor de ese dispositivo ${ }^{79}$. Además, como se ha visto a propósito de la cronología, la datación del hipocausto del establecimiento fregelano se fecha en una época aún más temprana, en plena primera mitad del siglo II a.C.

La presencia del hipocaustum absolutamente "vitruviano" no es la única novedad de la estancia 12. En efecto, varios fragmentos de conducciones cilíndricas de barro se encontraron esparcidos por doquier en las zonas próximas al ambiente. En el interior del hipocausto, y, muy especialmente, en el espacio entre el horno y la primera

77. Sin embargo, cfr. Delaine 1990 y Nielsen 1990, 22, sobre la importancia de la estandarización de las tejas en el desarrollo del hipocausto con pilae.

78. Vitr. V 10,2

79. Si se asume, claro está, que la tradición literaria se refiere a Orata y sus balnea pensilia en relación con la invención del hipocausto con pilae. Sobre una exégesis de la aportación de Orata, relacionada con la regularización de los módulos de las tejas, DELAINE 1990; sobre la cuestión FAGAN 1996. fila de pilae, aparecieron varios fragmentos más. Estos tubos, realizados con una mezcla especial de greda con efectos ignífugos, presentan incisiones reticulares en su exterior, probablemente para favorecer la adherencia de eventuales revestimientos o enfoscados, una vez puestos en obra. Ninguno de estos elementos se ha encontrado entero, por lo que no es posible reconstruir su longitud original. En algunos casos se conservan fragmentos de más de un tubo unidos perpendicularmente entre si, generando así ramificaciones laterales. Este dato demuestra la existencia de una red de tubos comunicantes, con ramificaciones que permitían canalizar el calor sobre una superficie mayor, que, naturalmente, no era el area del hypocaustum. Indica, además, que los tubos no estaban colocados entre horno e hypocaustum sólo para mejorar la transmisión de los gases entre el primero y el segundo ${ }^{80}$. Así mismo, permite descartar la posibilidad de que los tubos en cuestión asumieran exclusivamente el papel de chimeneas, puesto que las ramificaciones tienen poco sentido en un sistema de evacuación de humos. Por otra parte, el elevado número de fragmentos encontrados parece impedir considerarlos como conductos para introducir aire caliente en el interior de la estancia, aunque algunos podrían haber desempeñado este papel con respecto a las estancias limítrofes ${ }^{81}$. En consecuencia, puesto que la calefacción del suelo de la estancia 12 estaba garantizada por el hipocausto de pilae, la red de tubos serviría probablemente para calentar las paredes, o al menos algunas de ellas, de la estancia. Esta conclusión, de ser cierta, nos llevaría quizás a reconsiderar también las teorías sobre la cronología de la introducción del sistema de calefacción parietal por medio de tubos en los baños romanos, fijada tradicionalmente en torno a la mitad del siglo I a.C., para las paredes revestidas de tegulae mammatae, y a lo largo del siglo I d.C. para la introducción del sistema de tubuli (impressi parietibus tubi). En realidad, el sistema de calefacción parietal fregelano dista bastante del elaborado sistema de baterías de tubuli modulares, adosados a las paredes, bien conocido por la arqueo-

80. Esta posibilidad se descarta, por otra parte, vista la amplitud de la apertura rectangular (praefurnium), en el frente del horno.

81. Sobre este tipo de dispositivo, en todo caso poco frecuente, NIELSEN 1990, 17, con bibliografía en nota $38 ; 20$, notas 74 y 75 .

82. Sen. Ep. LXXX 25; cfr., por ejemplo, YEGÜL 1995, 363 ss. (con referencias bibliográficas). 
logía de establecimientos imperiales y al que parece referirse Seneca, considerándolo una innovación de sus días ${ }^{82}$. Aún así, constituye un ejemplo muy precoz, si bien limitado, de un intento de distribución del calor en los alzados. La deuda de este sistema de tubos con los sistemas de conductos tubulares subterráneos de los establecimientos griegos es plausible, aunque no necesariamente su disposición contra los alzados. De hecho, en contexto griego, sistemas de calefacción parietal similares se documentan, de momento, sólo para períodos más avanzados ${ }^{83}$.

La excavación del edificio de la I fase, ha permitido documentar bajo el alveus del caldarium, un gran canal recubierto con bóveda de cañón, realizada en opus figlinum, que, al parecer, se prolonga bajo el pavimento de otra estancia, contigua hacia el sur. La fuente de calor (horno) de este dispositivo se encontraba seguramente al norte del caldarium, en una zona no excavada por ubicarse bajo los pavimentos de la II fase. La conducción se presenta como la prolongación de la boca de salida de los gases del horno (praefurnium) ${ }^{84}$. Sistemas de calefacción situados por debajo de los alvei se encuentran ya en Gortys (IV a.C.) y en establecimientos greco-occidentales de los siglos IV (finales) y III a.C. También se documentan grandes canales de calefacción, a veces de doble conducto, en los baños republicanos, tipológicamente cercanos al de Fregellae, del siglo II a.C., caso de Musarna ${ }^{85}$, Cabrera del Mar ${ }^{86}$ y L'Almoina, entre otros, siendo este último descrito como hipocausto dotado de pilae ${ }^{87}$.

c) Bóvedas y decoración parietal

Como se ha mencionado con anterioridad, durante la excavación de la termas aparecieron numerosos fragmentos de dos tipos de materiales de barro cocido, absolutamente inusuales, que pertenecen a un sistema de cubierta abovedada. Se trata de elementos con forma de dovelas trapezoidales alargadas, por un lado, y de un tipo

83. Un caso de calefacción parietal por medio de tubos se encuentra en las termas romanas de Zevgolatio, en Corintia;otro en el gimnasio superior de Pérgamo (YEGÜL 1995, 363 s., con referencias bibliográficas).

84. Con este término entiendo aquí no el horno entero, sino la apertura en el frente de la cámara de combustión del horno, a través de la cual los gases irrumpían hacia el canal conectado con la fuente de calor y que, en ese sentido, constituía una prolongación del praefurnium stricto sensu (prae+furmus). También estos conductos son denominados hypocausta por numerosos investigadores.

85. Barbieri-Broise-Jovilet 1985; Broise-Jovilet 1991.

86. MARTÍN 2000.

87. Martín-Ribera 2000, 153.

88. Se han encontrado restos de plomo en varios fragmentos. Algunos de estos fragmentos, pertenecientes especial de tejas curvas, por otro. Ambos tipos de material, de excelente calidad, están fabricados de modo que encajan unos con otros.

En el trasdós de cada una de las dovelas, dos rebajes laterales en sentido longitudinal servían de asiento a las tejas. El intradós, en cambio, se presenta completamente liso. Cerca de cada una de sus extremidades, las dovelas están dotadas de una perforación en sección circular, que las atraviesa en sentido perpendicular. Desde esta perforación, tanto en el trasdós como en el intradós, parten sendos canalillos, que llegan hasta el final de ambos extremos de cada pieza. De este modo, las dovelas contiguas quedaban sólidamente fijadas entre sí, una vez rellenada la perforación y los canalillos con plomo ${ }^{88}$. Varias dovelas unidas con este procedimiento formaban un arco de medio punto. Varios arcos colocados en serie, a distancias regulares en el interior de un ambiente rectangular, generaban una armadura similar a un sistema de nervios o cimbras permanentes. La distancia entre arcos estaba condicionada por el tamaño de las tejas especiales curvas, que se asentaban sobre este soporte, encajando en los rebajes laterales del dorso de las dovelas y ensamblando entre sí, gracias a sendas pestañas en sus lados cortos. La curvatura y la longitud de las tejas es idéntica a las de las dovelas. Se generaba así la bóveda, cuyo intradós estaba recubierto de estuco de muy buena calidad, de color blanco hueso, mientras que el trasdós no presenta signos de haber estado revestido (figs. 6 y 7).

Se han encontrado dovelas de cuatro módulos distintos, diferenciados bien por su morfología, bien por su tamaño y curvatura. Al menos uno de estos módulos pertenece, con absoluta seguridad, a la I fase de las termas, demostrando que el edificio fregelano disponía de al menos una estancia abovedada en opus figlinum ya desde el siglo III a.C. Otro de los módulos, documentado en muy pocos fragmentos, parece pertenecer a un espacio abovedado de la II fase. Los dos módulos restan-

a dos dovelas contiguas, se conservaron aún unidos con esta grapa metálica. Sin embargo, en la mayoría de los casos el plomo no se ha conservado. A este respecto cabe destacar que, en numerosos casos, sólo se han encontrado conjuntos de fragmentos de la parte central de las dovelas, rotos precisamente a la altura de las perforaciones laterales y sin huellas de plomo. En cambio, en algunas zonas concretas, sólo aparecieron concentraciones de fragmentos de las extremidades de las dovelas, hecho que revela el procedimiento de recuperación del plomo empleado por los expliadores, tras la amortización del edificio.

89. Guitart 1976; Guitart-PAdrós 1990. En cierto sentido, también las bóvedas (dobles) obtenidas con ladrillos-dovela (FINCKER 1986) son herederas de la misma tradición. 


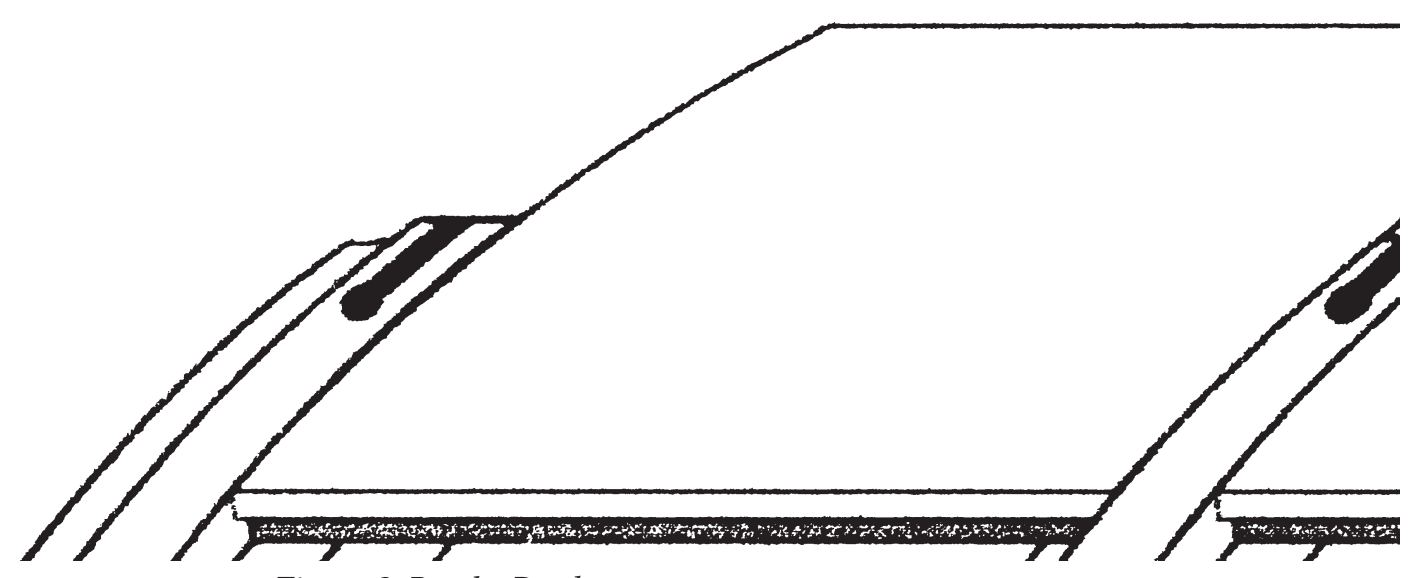

Figura 6. Bóveda. Dovelas cerámicas y tejas curvas.

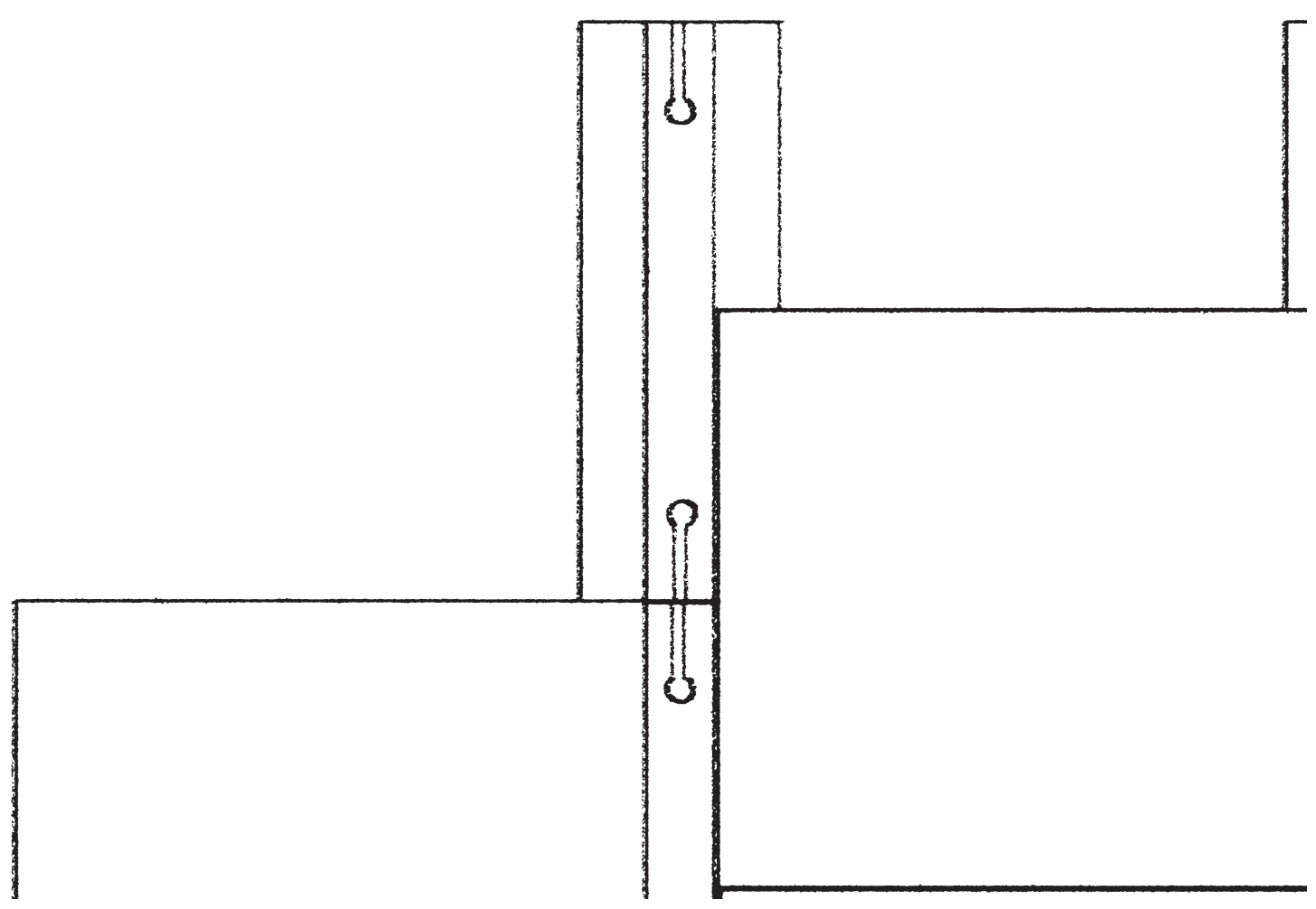

Figura 7. Bóveda. Posibilidades de la disposición de las tejas. 
tes, si bien con ligeras diferencias morfológicas, presentan características metrológicas idénticas, siendo, por tanto, probable su utilización en una única bóveda de casi seis metros de luz.

Este sistema de bóveda no cuenta con paralelos arquitectónicos exactos. Una solución similar, si bien con algunas importantes diferencias, se encuentra en las termas de Baetulo (Badalona), del segundo cuarto del siglo I a.C. ${ }^{89}$. Diferente, en cambio, es el sistema de bóveda por medio de tubos afusados documentado en las termas de Cabrera del Mar $^{90}$, de mediados del siglo II a.C., lo mismo que la cúpula de la tholos norte de los baños de Morgantina ${ }^{91}$, de principios del siglo III a.C. En Grecia, la arquitectura de piedra ofrece algunos ejemplos conceptualmente cercanos al ejemplo fregelano (adyton del templo de Apolo Clarios, Cisterna del teatro en Delos), si bien muy diversos desde el punto de vista de la estática. Una de estas bóvedas de piedra, del siglo III a.C., es la del adyton del Nekromanteion de Efira, que, como en Fregellae, se sirve de una armadura de arcos emparejados para la sujeción de las dovelas líticas.

La puesta en obra sobre rasante de una bóveda de tamaño y peso considerable, enteramente construida en opus figlinum, podría parecer (y lo es) una solución arriesgada. Sin embargo, la existencia de al menos una bóveda idéntica en las termas de I fase indica, que los arquitectos fregelanos dominaban ésta técnica ya desde el siglo III a.C. y, además, estaban satisfechos con el resultado, puesto que repitieron el modelo, incluso en formas aún más monumentales, en las termas de la II fase.

Las bóvedas fregelanas invitan también a una reconsideración del célebre y largamente discutido

\section{MARTín 2000.}

91. Allen 1974, que sugiere su posible dependencia de modelos norteafricanos; sobre el uso de la bóveda y la cúpula entre los púnicos, véase, CinTAS 1976 b, 89 s.; $101 \mathrm{ss}$.

92. Para una técnica púnica de cubierta hecha con mortero de barro (lutum punicum), Columela (IX 7,4; XI 3,54).

93. Vitruvio aconseja este mismo mortero para coger los laterculi de las pilae.

94. Para ilustrar algunas de las profundas diferencias en la comprensión del texto reproduzco aquí parcialmente tres de las traducciones que he consultado: a) "le volte siano preferibilmente in muratura e, nel caso di volte in legno, occorrerà rivestirle in cotto seguendo questo procedimento: si appendano alle travi per mezzo di uncini delle asticelle di ferro ad arco il più fitte possibile cosí da potervi far poggiare delle tegole senz'orlo; si otteranno delle volte poggianti interamente su di una struttura di ferro" (Testi); "The vaulted ceilings will be more convenient if they are made of concrete. But if they are o timber, they should be tiled underneath, in the following fashion. Iron pasaje de Vitruvio sobre las bóvedas de los baños. Vitruvio descrive y justifica su propuesta constructiva en los términos siguientes: Concamarationes vero si ex structura factae fuerint, erunt utiliores; sin autem contignationes fuer/rint, figlinum opus subiciatur. Sed hoc ita erit faciendum. Regualae ferreae aut arcus fiant, eaeque uncinis ferreis ad con/tignationem suspendantur quam creberrimis; eaeque regulae sive arcus ita disponantur, uti tegulae sine marginibus sedere in duabus invehique possint, et ita totae concamarationes in ferro nitentes sint perfectae. Earumque camararum superiora / coagmenta ex argilla cum capillo subacta liniantur; inferior autem pars, que ad pavimentum spectat, primum testa cum calce trullizetur, deinde opere albario sive tectorio poliatur. Eaeque camarae in caldariis si duplices factae fuerint, meliorem habebunt usum; non enim a vapore umor corrumpere / poterit materiem contignationis, sed inter duas camaras vagabitur.

El pasaje parece referirse con claridad a bóvedas de opus figlinum (= tegulae sine marginibus) apoyadas en un sistema de cimbras permanentes de hierro y colocadas bajo una techumbre de madera. En consecuencia, estas bóvedas no desempeñan el papel de cubierta propiamente dicha, sino que son simples techos abovedados, colocados bajo la armadura de madera de la cubierta (contignatio) ${ }^{92}$. El sistema de construcción propuesto por Vitruvio preveía la creación de un entramado mediante barras (?) o arcos (regulae sive arcus) de hierro, sólidamente sujetas con ganchos de hierro a contignationem y dispuestos en serie a intervalos regulares. El distanciamiento entre arcos o barras había de ser lo justo como para que las tegulae sine marginibus pudiesen asentarse entre cada pareja de barras o arcos. Una vez terminada la estructura, el intradós (inferior pars, que ad pavimentum spectat) de la bóveda

bars or arches are to be made and hung on the timber close together with iron hooks. And theese rods or arches are to be placed so far apart that the tile without raised edges may rest upon, and be carried by them; thus, the whole vaulting is finished resting upon iron" (Loeb); "Si las estancias abovedadas son de mampostería, resultarán más eficaces y provechosas, pero si fueran de madera colóquese debajo una falsa bóveda de barro, de la forma siguiente: háganse unas regletas (cabrios o unos arcos de hierro y mediante numerosos garfios de hierro también cuélguense del entramado: colóquense tales regletas o arcos de modo que puedan asentarse e introducirse las tejas sin formas bordes, entre regletas; así todo el conjunto abovedado resultará perfecto, ya que se apoyará en una estructura de hierro" (Alianza Editorial). Cfr. Giuliani 1975, 337, fgs. 7, 8, lams. 113, 114, 116.1, 117) con una curiosa reconstrucción de un supuesto revestimiento en opus figlinum de la cúpula de las Termas con Heliocamino de Villa Adriana; cfr. YEGÜL 1992, 366 ss. y notas 33 (con referencias bibliográficas) y 34 . 
resultante (camara) se impermeabilizaba con una capa de opus signinum (testa cum calce) revestida de estuco o escayola (opus albarium, opus tectorium), mientras que en el trasdós, las llagas del ensamblaje (camarae superiora coagmenta) se sellaban con mortero de barro mezclado con pelos ${ }^{93}$.

$\mathrm{El}$ pasaje genera varios interrogantes con respecto al valor semántico de algunos términos y expresiones, por lo que constituye aún objeto de debate ${ }^{94}$. Aún así, la expresión regulae sive arcus suspendatur ${ }^{95}$ parece referirse a dos sistemas de armadura distintas que, en todo caso, daban el mismo resultado: generaban el entramado de la bóveda ${ }^{96}$ sobre el cual se colocaban las tegulae sine marginibus ${ }^{97}$. La explícita mención del intradós y el trasdós de las camarae no deja lugar a dudas de que las estructuras de referencia son bóvedas.

Ahora bien, en Fregellae nos encontramos ante un sistema muy parecido al propuesto por Vitruvio. La única diferencia sustancial es que los arcus testacei (vel figlini) sustituyen aquí a las regulae ferreae aut arcus de la fuente literaria. En efecto, en las tejas curvas fregelanas, que descansan sobre los arcos, se puede reconocer una versión de las tegulae sine marginibus que Vitruvio tenía en mente. Naturalmente, la tipología especial de tejas de Fregellae no excluye que, en otros casos, pudiesen utilizarse otros tipos de testa, incluidas las tegulae planas con las aletas recortadas o sin ellas, como en Baetulo. También coincide con la descripción vitruviana la tipología del revestimiento del intradós de la bóveda, que consiste en

95. Cabe recordar que el empleo del verbo suspendere en arquitectura no significa "colgar" stricto sensu, como han pensado algunos autores, sino simplemente construir (montar) una estructura sobre el vacío, apoyándola en soportes especiales. Es este caso de la bóvedas (cameran suspendere) y de las suspensurae y suspensiones vitruvianas. Estas últimas se asocian por algunos con la invención del hipocausto por Orata en virtud de expresiones como primus balneola suspendid o invenerit balineas pensiles etc., transmitidas por la tradición literaria; es posible que la expresión balneum suspendid de la inscripción ILS 5711 (Pitinum Pisaurense), no se refiera a la dotación de los balnea con hipocausto (así FAGAN 1996, 57, nota 12), sino a la construcción ex novo de balnea dotados de salas abovedadas.

96. Algunos autores españoles entienden, que las concamerationes son las cámaras bufas de las paredes, obtenidas mediante tegulae mammatae y clavi coctiles (así por ejemplo, SAnz Gamo 1987; Fernández OCHOA-García EnTERo 2000, passim etc.). El pasaje de Vitruvio, al menos, no admite una traducción-interpretación en ese sentido.

97. La frase regulae ferreae aut arcus... uncinis ferreis ad contignationem suspendantur quam creberrimis no parece signifi- varias capas superpuestas de argamasa de óptima calidad y acabado de estuco. El trasdós, en cambio, no presenta signo alguno de revestimiento, aunque tampoco delata desperfectos o desgaste por efecto de agentes atmosféricos, ni muescas u otros signos susceptibles de ser atribuidos a la fijación de una protección superpuesta. En consecuencia, las bóvedas de Fregellae no constituían verdaderas cubiertas, sino que servían de techos, colocados bajo la cubierta del edificio ${ }^{98}$.

Una característica muy llamativa de las salas abovedadas de las termas fregelanas de ambas fases es la asociación de las bóvedas de opus figlinum con series de telamones exentos de terracota $^{99}$, altos entre 0,75 y $0,80 \mathrm{~m}$. A esta conclusión conducen los numerosos fragmentos de estas figuras (algunas encontradas prácticamente íntegras) aparecidos en el interior de las termas. Los telamones pertenecen a dos tipos distintos, el del sátiro jóven, por un lado, y el del sátiro viejo, por otro, distinguiéndose también diferencias morfológicas en el interior de cada tipo. Algunos de los fragmentos del tipo de sátiro jóven aparecieron sellados bajo los pavimentos de la II fase, hecho que, junto a la aparición de dovelas cerámicas en las mismas estratigrafías, demuestra la existencia de al menos una sala abovedada y decorada con series de telamones, ya desde la I fase del edificio, en el siglo III a.C. Este dato concuerda con los elementos estilísticos de las figuras de los sátiros jóvenes, cuyos modelos se remontan al siglo IV a.C. ${ }^{100}$ En cambio, el tipo de sátiro viejo, no documentado en relación con la I fase, aparece como claro deudor de las tendencias barrocas

car que la pesada estructura de hierro "se colgaba" con garfios desde la armadura de madera de la cubierta; más bien hay que entenderla en el sentido de que esta armadura férrea de la bóveda, bien sujeta con muchos unci$n a$, "se levantaba" hasta $(a d=a p u d)$ la contignatio. Vitruvio sencillamente emplea el término adecuado para la puesta en obra de un arco o una bóveda: suspendatur.

98. La descripción pormenorizada de las bóvedas fregelanas y su relación con el texto de Vitruvio serán objeto de una futura publicación.

99. Coarelli 1998, 61.

100. Sobre el tema KAENEL 2000, con bibliografía. Sobre los telamones en general, SCHMIDT COLINET 1977; telamones en Italia central, JANNOT 1984 (pero, cfr. KAENEL 2000); sobre su escasa difusión en Grecia, STEFANIDOU TIBERIOU 1988; sobre terracotas arquitectónicas con rostro de sátiro joven en España (Ampurias, La Encarnación, etc.), una síntesis en RAMALLO ASENSIO 1999 (con bibliografía), en especial 163-166.

101. KaEnel 2000, 153

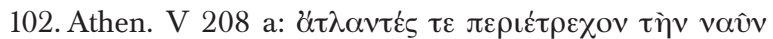

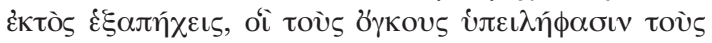

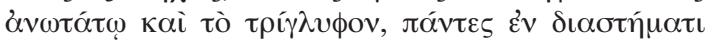
$<\sigma v \mu \mu \varepsilon \dot{\tau} \rho \omega \varphi)>\beta \varepsilon \beta \hat{\omega} \tau \varepsilon \varsigma$. 
del arte pergameno del Gran Altar ${ }^{101}$, hecho que hace remontar su cronología a un momento posterior a la realización del friso de Pérgamo. También este dato concuerda con la estratigrafía de la II fase del edificio y su marco cronológico (primera mitad del siglo II a.C., probablemente entre segunda y tercera década).

La disposición de estas figuras contra las paredes de las estancias abovedadas debería seguir el esquema conocido por la cita de Ateneo ${ }^{102}$ sobre la decoración de los flancos exteriores de la nave Syrakosía, obsequio regio de Hierón II de Siracusa al recién ascendido al trono de Egipto Prolomeo IV Filopator (coronación en el 221 a.C.) ${ }^{103}$. En este caso, las series de telamones jóvenes de la(s) bóveda(s) de la I fase de las termas de Fregellae, serían incluso anteriores a la donación de la Syracosía. El renovado gusto por las figuras de los atlantes-telamones conoce gran difusión en Sicilia a partir de finales del siglo IV a.C. y cuenta con numerosos reflejos en Magna Grecia y Etruria. En esta misma corriente, en la que, naturalmente, estaría implicada la misma Roma, se inscriben también las series de Fregellae de ambas fases, que, durante la II fase, de comienzos del siglo II a. C., adoptan el tipo del sátiro viejo, en sustitución (total o parcial) del tipo del sátiro joven utilizado en la fase anterior. En el ámbito termal, el modelo pervive aún durante el siglo I a.C., como pone de manifiesto su presencia en el tepidarium de las Termas del Foro pompeyanas ${ }^{104}$.

Precisamente, la disposición de los telamones en el tepidarium de las Termas del Foro de Pompeya y la descripción de la Syrakosía transmitida por Ateneo, permiten la reconstrucción de la relación bóvedas-telamones en las termas de Fregellae de ambas fases. Sin extendernos ahora en relaciones numéricas, cabe indicar la más que probable relación entre "nervios"-arcos de las bóvedas y telamones comprendidos entre sendas cornisas horizontales. Con o sin nichos entre telamones, se lograría, en todo caso, un efecto estético realísta de sujeción de la bóveda por parte de las figuras, acentuado por la policromía de las paredes y de las figuras mismas. Las alusiones cosmológicas de este esquema parecen evidentes.

\section{Épílogo}

Esta breve exposición y discusión de algunos

103. A. Schmidt Colinet (Schmidt Colinet 1977, 48; 132; 243), piensa que se trata de Ptolomeo III.

104. Castiglione 1978. datos de las termas mediorrepublicanas de Fregellae ponen de manifiesto la importancia del edificio para el estudio del termalismo romano. Antes de la aparición del conjunto fregelano, todo estudio sobre los orígenes de las termas romanas arrancaba y se basaba en la periodización de las Termas Estabianas. Para el siglo III y los comienzos del II a.C., Fregellae brinda ahora un panorama evolutivo algo distinto al que se podía intuir a través del establecimiento pompeyano. Sirva un sucinto repaso de las principales novedades que aportan las dos fases del edificio fregelano como ilustración final de la presente contribución:

- Existencia en el Lacio, ya desde la primera mitad o mediados del siglo III a.C., de establecimientos termales monumentales, de alta calidad arquitectónica, con variedad de servicios y dotados de dispositivos de alta tecnología. El establecimiento fregelano de I fase cuenta con caldarium dotado de gran alveus colectivo, calefactado por medio de un conducto subterráneo, comparable a los sistemas de los $\beta \alpha \lambda \alpha v \varepsilon \hat{\imath} \alpha$ greco-occidentales contemporáneos. También cuenta con otras salas especializadas, al parecer articuladas de manera similar a los futuros balnea de núcleo tripartito. $\mathrm{Al}$ menos una de las estancias estaba dotada de labrum y otra, al parecer, con banco corrido.

- Confirmación de la existencia, durante las primeras décadas del siglo II a.C., del modelo de balneae, con sectores netamente separados para hombres y mujeres, dotados de las clásicas salas de baño, incluido el sudatorium en el sector masculino, y, probablemente con palestra.

- Innovaciones tecnológicas en relación con los sistemas de calefacción de los baños. Destaca la existencia en el edificio de la II fase (primera mitad del siglo II a.C.) de un hipocausto de pilae completamente desarrollado, sólo comparable con sus herederos del siglo I a.C. El dispositivo de Fregellae demuestra que la pretendida invención del hipocausto por Sergius Orata a principios del siglo I a.C. es un mito. Así mismo, se ha documentado la existencia de un sistema de calefacción mediante tubos, casi seguramente aplicado a las paredes del sudatorium. 
Se han documentado importantes soluciones arquitectónicas en relación con la construcción de bóvedas. Ya desde la I fase, las termas fregelanas cuentan con bóvedas de cañón de opus figlinum, realizadas con arcos modulares que actúan como nervios o cimbras permanentes y con tejas curvas especiales colocadas entre parejas de arcos. Este sistema, notable y sin paralelos exactos, permite una lectura coherente del pasaje de Vitruvio sobre las bóvedas de los baños (Vitr. V 10,3). Pequeñas bóvedas de dovelas cerámicas se documentan también en el conducto de calefacción del alveus de la I fase. La variada tipología y la calidad de los materiales testaceos empleados en la construcción de las termas (incluidos los numerosos tipos de losetas pavimentales) ponen de manifiesto la alta especialización de los alfares locales.

- Decoración de las estancias abovedadas con filas de telamones de terracota ya desde la I fase. Predominio de pautas helenísticas en todas las manifestaciones arquitectónicas y artísticas del conjunto.

Todo lo anterior y otros muchos aspectos del complejo fregelano, que no han podido ser tratados aquí, permiten dilucidar varias incógnitas de las costumbres relacionadas con la práctica del baño de la sociedad romano-itálica durante los siglos III y II a.C. y conducen hacia una aproximación más sólida a las manifestaciones arquitectónicas y culturales precoces del fenómeno balnear en Roma y su inmediato entorno.

\section{Bibliografía}

Almagro Gorbea-Álvarez Sanchís 1993: AlmagroGorbea, M., Álvarez-Sanchís, J.R., "La sauna de Ulaca: saunas y baños iniciaticos en el mundo céltico", Cuadernos de Arqueología de la Universidad de Navarra 1, 177-232.

BARbieri-Broise-Jovilet 1985: Barbieri, G., Broise, H., Jovilet, V., "Musarna I. I bagni tardorepubblicani", BdA 29, 29-38.

BlaCKMAN 2001: Blackman, D., "Archeology in Greece 2000-2001", AR 47.

Bouet 2000: Bouet, A., "Les modèles thermaux et leur diffusion en Gaule", en FERnÁNDEZ OCHOA-GARCÍA ENTERO 2000, 35-46.

Broise 1994: Broise, H., "La practique du bain chaud par immersion en Sicile et dans la péninsule italique à l'époque hellénistique", Xenia Antiqua 3, 17-32.

Broise-Jovilet 1991: Broise, H., Jovilet, V., "Le bain en
Etrurie à l'époque hellénistique", en Les Thermes Romains. Actes du Colloque de Rome, Roma (EFR).

Broise-Jovilet 1993: Broise, H., Jovilet, V., MEFRA, 444-445.

Broise-Jovilet 1994: Broise, H., Jovilet, V., MEFRA, 457-459.

Broise-Lafon 1980: Broise, H., Lafon, X., "Les villes litorales de la zone de Sperlonga", Archeologia Laziale III, $111 \mathrm{ss}$.

BroIse-ScheId 1987 : Broise, H. y Scheid, J., Le balneum des Frères Arvales. Recherches archéologiques à lLa Magliana, Roma.

Brown 1951: Brown, F.E., Cosa I. History and Topography, (MAAR XX), Roma.

CAPUTO 1991: Caputo, M., "La decorazione parietale di primo stile nel Lazio", AFLPer XXVIII, 213-276.

Castiglione 1978: Castiglione, L., "Zur plastik von Pompeij", en Andreae, B.-Kyrieleis, H. (ed.), Neue Forschungen in Pompeji. 1975, 212 ss.

Champeaux 1982: Champeaux, J., Fortuna. Recherches sur le culte de la Fortune à Rome et dans le mond romain des origines à la mort de César, I, Rome.

Champeaux 1987: Champeaux, J., Les transformations de Fortuna sous la République, II, Rome.

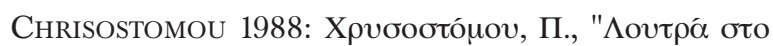

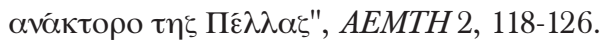

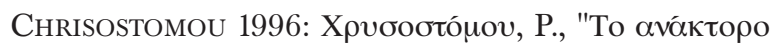

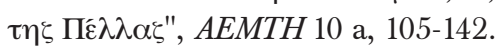

CoArelli 1981: Coarelli, F., "Il Campo Marzio occidentale. Storia e topografia", MEFRA 89 (2), 807-846.

CoArelli 1982: Coarelli, F., Lazio. Guide archeologiche Laterza. Roma-Bari.

CoArelli 1983: Coarelli, F., Il Foro Romano. Periodo arcaico. Roma $1992^{3}$.

CoArelli 1984: Coarelli, F., Roma sepolta, Roma.

CoARelli 1988: Coarelli, F., Il Foro Boario. Dalle origini alla fine della repubblica, Roma $1992^{2}$.

CoArelli 1994: Coarelli, F., "Due fregi da Fregellae: un documento storico della Prima Guerra Siriaca?", Ostraka III. 1, 93-108.

CoArelli 1997: Coarelli, F., Il Campo Marzio. Dalle origini alla fine della repubblica, Roma.

CoArelli 1998: Coarelli, F., Monti, P.G., Fregellae. I. Le fonti, la storia, il territorio, Roma.

COARelli 2000: Coarelli, F., "L'inizio dell'opus testaceum a Roma e inell'Italia romana", en Boucheron, P., Broise, H. y ThÉBert, Y. (eds.), La brique antique et 
médiévale. Production et commercialisation d'un matériau, Actes du colloque international, Saint-Cloud, 16-18 novembre 1995, Roma.

Conche 1999: Conche, F., "Rue Leca", en Bouiron, M., Guilcher, A. y Pagni, M., (eds.), Marseille. Trames et paysages urbains de Gyptis au roi René, Préactes Coll. Intern. de Marseille. Centre Méditerranéen de Commerce International, Marseille, 90-92.

Crova 1956: Crova, B., "Le terme romane nella Campania", AttiCStR VIII, 271-288.

Cultera 1938: Cultera, G., "Siracusa. Rovine di un antico stabilimento idraulico in contrada Zappalà", $N S c$, 261-301.

De Albentiss 1990: De Albentiis, E., La casa dei romani, Milán.

De Amicis 1991: De Amicis, A. et al., Vecchi scavi, nuovi restauri. Museo Archeologico Nazionale-Taranto. Dal 14 marzo 1991, 1991.

De Angelis 2001: De Angelis, F., "Archeology in Sicily 1996-2001", AR 47.

De Cazanove-Jovilet 1984: De Cazanove, O. Y Jovilet, V., "Musarna (Viterbe), la cité étrusque", MEFRA, 530-534.

Degbomond 1984: Degbomond, J.M., Hypocaustes. Le chauffage par hypocauste dans l'habitat privé. De la place St.-Lambert à Liège à l'Aula Palatina de Trèves, Lieja.

Delaine 1988: DeLaine, J., "Recent Research on Roman Baths", JRA 1, 11-32.

Delaine 1989: DeLaine, J., "Some Observations on the Transition from Greek to Roman Baths in Hellenistic Italy", MediArch 2, 111-125.

Delaine 1993: DeLaine, J., "Roman Baths and Bathing", JRA 6, 348-358 (recensiones críticas).

Delorme 1960: Delorme, J., Gymnasion. Étude sur les monuments consacrès à l'éducation dans la Grèce ancienne, Paris.

Di CAPUA 1929: Di Capua, F., "I valetudinari e le stazioni di cura a Stabia al tempo degli antichi romani", Atti XIX Congresso nazionale d'Idrologio, Napoli, 83-88.

Di CAPUA 1940: Di Capua, F., "Appunti sull'origine e sviluppo delle terme romane", Accademia di Architettura, Lettere e Belle Arti 20, Napoli, 81-160.

EsCHEBACH 1973: Eschebach, H., "Untersuchungen in der Stabianer Thermen zu Pompeii", RM 80, 235242.

Eschebach 1979: Eschebach, H., Die Stabianer Thermen in Pompeji, Berlin.

FABBRICOTTI 1976: Fabbricotti, E., "I bagni nelle prime ville romane", CronPomp 2, 29-11.

FAGAN 1996: Fagan, G.G., "Sergius Orata: Inventor of the Hypocaust?", Phoenix 50, 56-66.

FAGan 2001: Fagan, G.G., "The Genesis of the Roman Public Bath: Recent Approaches and Future Directions", AJA 105.3, 403-426.

Fernández OchoA-García Entero 2000: Fernández Ochoa, C. y García Entero, V. (eds.), Termas romanas en el occidente del Imperio, II Coloquio internacional de Arqueología en Gijón. Gijón 1999, Gijón.

FiORINI 1988: Fiorini, C., "Edificio di età repubblicana in Via Sistina", Quad.Top. Ant. X, 45-57.

FinCKer 1986: Fincker, M., "Les briques claveaux: un matériau de construction spécifique des Thermes Romains", Aquitania 4, 143-150.

GAGÉ 1958: Gagé. J., "Classes d'age, rites et vêtements dans l'ancien Latium. À propos de la garde-robe du roi Servius Tullius et de la déesse Fortuna", Cahiers Internat. de Sociol. 24, 34-64.

Gallina 1970: Gallina, A., s.v. "Cuma", en EAA suppl., $273 \mathrm{~s}$.

Gauthier-Hatzopoulos 1993: Gauthier, Ph. Y Hatzópoulos, M., "La loi gymnasiarchique de Beroia", Meletemata 22, 150 ss.

GinouvÉs 1959: Ginouvès, R., L'établissement thermal de Gortys d'Arcadie, Paris.

GiNOuvÉs 1962: Ginouvès, R., Balaneutikè. Recherches sur le bain dans l'Antiquité grecque, Paris (BEFAR 200).

GiUliani 1975: Giuliani, C.F., "Volte e cupole a doppia calotta in età Adrianea", RM 82, 329-342.

Guitart 1976: Guiart Duran, J., Baetulo. Topografía, Arqueología, Urbanismo e Historia, Badalona.

Guitart-Padrós 1990: Guiart Duran, J. y Pardós, P., Baetulo. Cronología y significación de sus monumentos, en Trillmich, W. y Zanker, P. (eds.), Stadtbild und Ideologie. Die Monumente Monumentalisierung hispanischer Städte zwischen Republik und Kaiserzeit, (Madrid 1987), Munich.

HaRTMANN 1920: Hartmann, R., "Das Laconicum der römischen Thermen", $R M$ 35, 152-169.

Hesnard-Moliner-Conche-Bouiron 1999: Hesnard, A., Moliner, M., Conche, F. y Bouiron, M. (eds.), Parcours de villes. Marseille: 10 ans d'archéologie. 2600 ans d'histoire, Aix-en-Provence.

Hermary-Hesnard-Treziny 1999: Hermary, A., Hesnard, A. y Treziny, H. (dirs.), Marseille greque. La cité phocéenne (600-49 av. J.-C.), París.

IsLer 2000: Isler, H.P. Monte Iato. Guida archeologica, 
Palermo.

Isler KerenYi 1976: Ribi, E.A., Isler Kerenyi, C., "Die Stützfiguren des griechischen Theaters von Iatas", in Bloesch, H.-Isler H.P. (ed.), Studia Ietina I, 1976, 13 ss.

JANNOT 1984: Jannot, J.-R., "Une orde étrusque à telamons?", MEFRA XCVI, 585 ss.

JoHANnOwski 1961: Johannowski, W., "Relazione preliminare sugli scavi di Cales", $B d A$ 46, 258-268.

JOHANNOWSKI 1982: Johannowski, W., "Considerazioni sullo sviluppo urbano e la cultura materiale di Velia", PP 37, 243-247.

KAENEL 2000: Känel, R., "Ein etruskisch-italischer Telamon in Genf", AntK 45, 148-155.

KunZe-SchleIf 1944: Kunze, E, Schleif, H., IV Bericht über die Ausgrabungen in Olympia 1940 und 1941, Berlin.

LAFON 1991: Lafon, X., "Les bains privés dans l'Italie romaine au Iie siècle av. J.C.", en Les Thermes Romains. Actes du Colloque de Rome, Roma (EFR), 197-114.

MARTín 2000: Martín A., "Las termas republicanas de Cabrera del Mar (Maresme, Barcelona)", en Fernández Ochoa-García Entero 2000, 157-162.

Martín-Ribera 1999: Martín Jordá, C., Ribera i Lacomba, A., Las termas romanas de l'Almoina, (Quaderns de Difusió arqueològica 3), Valencia.

Martín-Ribera 2000: Martín Jordá, C., Ribera i Lacomba, A., "Un caso precoz de edificio termal: los baños republicanos de Valentia", en FERnándeZ OCHOA-GARCÍA ENTERO 2000, 151-156.

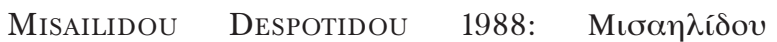

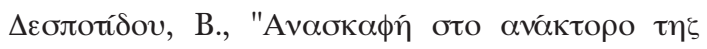

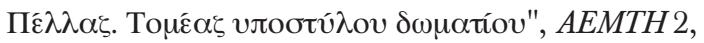
101-112.

Monti 1994: Monti, P.G., "Il sistema di rifornimento idrico delle colonie latine medio-repubblicane: il caso di Fregellae", en La ciutat en el món romà, Actes, XIV Congrés Internacional d'Arqueologia Clàssica, Tarragona 5-11/9/1993, II, 291-292.

Monti 1995: Monti, P.G., Via Latina, Roma.

Morena-Counord 1994: Morena, M. y Counord, D., Antipolis municipe romain. Catalogue de l'exposition. Musée d'histoire et d'archéologie. Bastion SaintAndré. Antibes.

NielSEN 1985: Nielsen, I., "Considerazioni sulle prime fasi dell'evoluzione dell'edificio termale romano", AnalRomInstDan 14, 81-112.

Nielsen 1990: Nielsen, I., Thermae and balnea. The
Architecture and Cultural History of Roman Public Baths, 2 vols., Aarhus.

Nolla 2000: Nolla, J.M., "Las termas republicanas en Hispania", en Fernández OchoA-García Entero 2000, 47-57.

Orlandini-ADAMESTEANU 1960: Orlandini, P., Adamesteanu, D., "Gela. Nuovi scavi: l'impianto greco di bagni pubblici presso l'ospizio", NSc 14, 181 ss.

Pestalozza 1951: Pestalozza, U., Religione mediterranea, Milano.

Pouilloux 1960: Pouilloux, J., "Un prototype arcadien des thermes antiques", REG 73, 455-459.

Ramallo Asensio 1999: Ramallo Asensio, S.F., "Terracotas arquitectónicas de inspiración itálica en la Península Ibérica", en Bendala Galan, M. et al. (eds.), El ladrillo y sus derivados en la época romana, Madrid, 159-178.

REBUfFat 1991: Rebuffat, R., "Vocabulaire thermal. Documents sur le bain romain", en Les Thermes Romains. Actes du Colloque de Rome, Roma (EFR), 10-23.

RiberA 1993: Ribera i Lacomba, A., "Valentia: desarrollo urbano al final de la República", en Mangas, J. (ed.), Italia e Hispania en la crisis de la república romana, Actas del III Congreso Hispano-Italiano (Toledo, 2024 septiembre 1993), Madrid 1998, 355-373.

RiberA 1998: Ribera i Lacomba, A., La fundació de València. La ciutat a l'època romanorepublicana (segles II-I a.C.), Etudis Universitaris 71, (Institució Alfons el Magnanim), Valencia.

Sanz Gamo 1987: Sanz Gamo, R., "Algunos materiales romanos utilizados en la construcción de las concamerationes", Oretum 3, 225-236.

Schmidt-Colinet 1977: Schmidt-Colinet A., Antike Stützfiguren. Untersuchungen zu Typus und Bedeutung der menschengestaltigen Architekturstütze in der griechischen und römischen Kunst, Frankfurt.

SGobbo 1928: Sgobbo, I., "Terme flegree ed origine delle terme romane", AttiCStR I, 186-194.

Sironen 1990: Sironen, T. , "Una tessera privata del II secolo a.C. da Fregellae", ZPE LXXX, 116-120.

Staccioli 1955: Staccioli, R.A., "Tracce di terme 'pompeiane' a Roma'", Amor di Roma, 391-401.

Staccioli 1955 b: Staccioli, R.A., "Le rotonde delle terme pompeiane", $A r c h C l$ VII.1, 75-84.

Staccioli 1958: Staccioli, R.A., "Sugli edifici termali minori", $\mathrm{Arch} C l$ 10, 273-278.

StACCIOLI 1961: Staccioli, R.A., "Terme minori e balnea nella documentazione della Forma Urbis", ArchCl 


\section{$13,92-102$}

Stefani 1945: Stefani, E., "Grottarossa. Ruderi di una villa di età repubblicana", NSc 1944-1945, 60 ss.

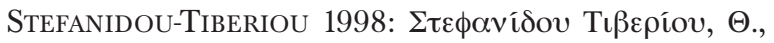

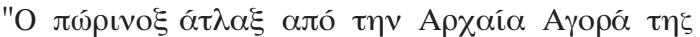

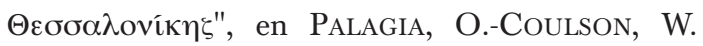
(eds.), Regional Schools in Hellenistic Sculpture, Proceedings of an International Conference Held at the American School of Classical Studies at Athens. March 15-17, 1996, Oxford.

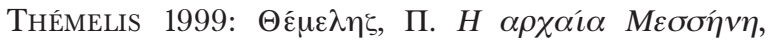
Atenas.

Tocco 1976: Tocco, G., "Saggi di scavo nella città e nella necropoli di Cuma", en La Magna Grecia nell'età romana. Atti del XV Convegno di studi sulla Magna Grecia, Taranto 1975, Nápoles, 485-496.

Torelli 1984: Torelli, M., Lavinio e Roma. Riti iniciatici e matrimonio tra Archeologia e Storia, Roma.
Torelli 1990: Torelli, M., "Riti di passaggio maschili di Roma arcaica", MEFR 102-1, 93-106.

Torelli 1991: Torelli, M., "Il 'diribitorium' di Alba Fucens e il 'campus' eroico di Herdonia", en Cominità indigene e problemi della romanizzazione nell'Italia centro meridionale, Bruxelles-Rome, 39-63.

VALLET-Villard-Auberson 1983: Vallet, G., Villard, P., Auberson, P., Megara Hyblaea III. Guide des fouilles, Roma (EFR).

Yegül 1979: Yegül, F.K., "The Small City Bath in Classical Antiquity and a Reconstraction Study of Lucian's 'Baths of Hippias'", ArchCl 31, 108-131.

YeGÜL 1995: Yegül, F.K., 1995, Baths and Bathing in Classical Antiquity, New York-Cambridge Mass.London.

Zevi 1976: Zevi, F., "Alatri" in Hellenismus in Mittelitalien. Kolloquium in Göttingen von 5 bis 9 Juni 1974, II, Göttingen, 84-89. 